Fall 12-20-2019

\title{
Perspectives of Occupational Therapy Practitioners on Benefits and Barriers on Providing Occupational Therapy Services via Telehealth
}

Taylor Corey

University of St. Augustine for Health Sciences

DOI: https://doi.org/10.46409/sr.PDFY2999

Follow this and additional works at: https://soar.usa.edu/capstones

Part of the Health Information Technology Commons, and the Occupational Therapy Commons

\section{Recommended Citation}

Corey, T. (2019). Perspectives of Occupational Therapy Practitioners on Benefits and Barriers on Providing Occupational Therapy Services via Telehealth. [Doctoral project, University of St Augustine for Health Sciences]. SOAR @ USA: Student Capstone Projects Collection. https://doi.org/10.46409/sr.PDFY2999

This Capstone is brought to you for free and open access by the Student Research at SOAR @ USA. It has been accepted for inclusion in Student Capstone Projects by an authorized administrator of SOAR @ USA. For more information, please contact soar@usa.edu, erobinson@usa.edu. 
PERSPECTIVES OF OCCUPATIONAL THERAPY PRACTITIONERS ON BENEFITS AND BARRIERS ON PROVIDING OCCUPATIONAL THERAPY SERVICES VIA TELEHEALTH by Taylor A Corey

A Capstone Presented in Partial Fulfillment of the Requirement for the Degree of DOCTOR OF OCCUPATIONAL THERAPY University of St. Augustine for Health Sciences December, 2019 
PERSPECTIVES OF OCCUPATIONAL THERAPY PRACTITIONERS ON BENEFITS AND

BARRIERS ON PROVIDING OCCUPATIONAL THERAPY SERVICES VIA TELEHEALTH by

Taylor A Corey

has been approved

December, 2019

APPROVED:

Susan MacDermott, OTD, OTR/L, Doctoral Coordinator

Becki Cohill, OTD, OTR/L, Doctoral Coordinator

Erin Schwier, EdD, OTD, OTR/L, Program Director

ACCEPTED AND SIGNED:

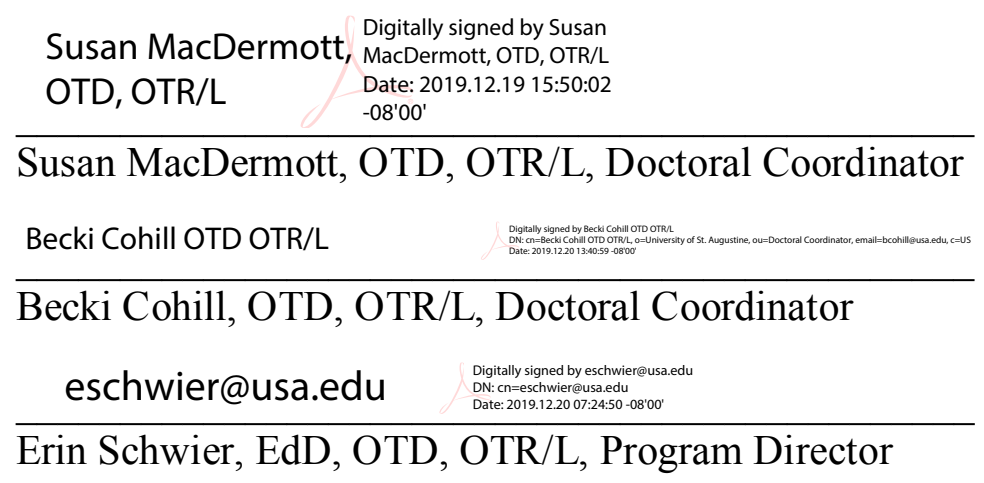




\section{Table of Contents}

CHAPTER I. Introduction $\quad 5$

$\begin{array}{ll}\text { Background } & 5\end{array}$

$\begin{array}{ll}\text { Statement of Problem } & 6\end{array}$

$\begin{array}{ll}\text { Purpose Statement } & 7\end{array}$

$\begin{array}{ll}\text { Rationale for Project } & 7\end{array}$

$\begin{array}{ll}\text { Significance of the Project } & 10\end{array}$

$\begin{array}{ll}\text { Project Objectives } & 10\end{array}$

$\begin{array}{ll}\text { Definition of Terms } & 11\end{array}$

$\begin{array}{ll}\text { Assumptions, Limitations, and Delimitations } & 12\end{array}$

CHAPTER II. Literature Review 13

CHAPTER III. Project Description 19

Planned Materials, Design, and Participants $\quad 19$

$\begin{array}{ll}\text { Planned Timeline and Procedure } & 21\end{array}$

$\begin{array}{ll}\text { Actual Methods and Timeline } & 23\end{array}$

CHAPTER IV. Results and Analysis $\quad 24$

$\begin{array}{ll}\text { Data Analysis } & 24\end{array}$

$\begin{array}{ll}\text { Results } & 25\end{array}$

CHAPTER V. Discussion and Conclusion $\quad 45$

$\begin{array}{ll}\text { Discussion } & 45\end{array}$

$\begin{array}{ll}\text { Implication to OT } & 51\end{array}$

$\begin{array}{ll}\text { Limitations } & 52\end{array}$

$\begin{array}{ll}\text { Future Studies } & 54\end{array}$ 
$\begin{array}{ll}\text { Conclusion } & 55\end{array}$

$\begin{array}{ll}\text { References } & 57\end{array}$

APPENDIX A. Interview for Service Providers Who Have Used Telehealth 65

APPENDIX B. Interview for Service Providers Who Have Never Used Telehealth 68

APPENDIX C. Survey Service Providers Who Have Used Telehealth 70

APPENDIX D. Survey Service Providers Who Have Used Telehealth 75

APPENDIX E. Email and Survey Post Introduction 79

APPENDIX F. Deliverables to San Diego Regional Center $\quad 81$

APPENDIX G. Deliverables to HM Systems 86 


\section{CHAPTER 1. Introduction}

\section{Background}

The advancement of technological services has shaped medicine in addition to the interaction between healthcare officials and patients. Nearly all areas within the medical model have been influenced and positively affected by information and communication technologies (ICT), including the scope of practice of occupational therapy (OT) (Cason, 2014). Information and communication technologies provides an alternative method of face-to-face occupation therapy. With the advancement of ICT services, this evolution of technology has emerged as a new type of service delivery model in the realm of OT - telehealth (Cason, 2014). The American Occupational Therapy Association (AOTA) defines telehealth "as the application of evaluative, consultative, preventative, and therapeutic services delivered through information and communication technology" (2018, p. 1).

Occupational therapy services traditionally provided in person, now, with the emergence of telehealth services, occupational therapists can provide their services from a different geographical location than their client (Gardner, Bundy, \& Dew, 2016). The World Federation of Occupational Therapists (WFOT) recognizes telehealth as an "appropriate delivery model for occupational therapy" (WFOT, 2014, p. 38), that "may improve access to services within clients' communities and 'strengthen and extend comprehensive habilitation and rehabilitation services' via the transfer of knowledge and skills from remote specialists to local health-care providers through consultation and mentoring relationships" (WFOT, 2014, p. 38). Occupational therapy services delivered via telehealth are not considered a separate and distinctive intervention, but rather an alternative way to provide OT services traditionally delivered in person (Cason, 2014). 
AOTA recognizes telehealth as a service delivery model to help support engagement of occupations for "habilitation, rehabilitation, and promotion of health and wellness for clients with disabilities- and non-disability related needs" (AOTA, 2014, S1). Within OT, telehealth can be used in every major practice area including early intervention, children, and youth; productive aging; health and wellness; mental health; rehabilitation, disability, and participation; and work and industry (Cason, 2012b). As a service delivery model, telehealth removes barriers and improves access of care and specialists, specifically in underserved and rural areas (Cason, 2012b). Some studies suggest that when comparing outcomes of telehealth and in-person services, telehealth may have better outcomes with some populations (Cason, 2014). The evidence is positive that telehealth is an effective service delivery model for occupational therapy (AOTA, 2018). However, there is little research on occupational therapists' perspective and experiences on telehealth services (Dunleavy, Preissner, \& Finlayson, 2013).

\section{Statement of Problem}

The key to the implementation of a successful telehealth program is the provider's acceptance (Serwe, 2018). Providers tend to view telehealth less positively and have more concerns than the clients (Serwe, 2018). Dunkley, Pattie, Wilson, and McAllister (2010) found that due to the inherent technical difficulties that come with the use of technology, these difficulties have a chance to outweigh the potential benefits of the program. Providers will only participate in telehealth if it is based on the need of the client (Serwe, 2018). While concerns about the technology exist, there are factors that lead to users' satisfaction with it. Some of these factors include familiarity with telehealth software, previous experience with telehealth, and telehealth training (Serwe, 2018). Research is limited on the perceived barriers and provider's concerns when it comes to telehealth, especially when it comes to occupational therapist 
practitioners. In order to fully understand the provider's experience and to properly support their experiences and needs with telehealth, research must be conducted to gain a better understanding of the positive and negative perspectives surrounding telehealth in order to best promote provider acceptance for it (Serwe, 2018).

\section{Purpose Statement}

The purpose of this project is to gain a better understanding of the provider's perspectives about the strengths and barriers of OT services provided via telehealth. Data will be collected with surveys and interviews to determine specific factors on whether or not therapists choose to provide services through telehealth. The results can help explore the issues and concerns therapists have when it comes to telehealth as a service delivery model.

\section{Rationale for Proposed Project}

Telehealth is an emerging practice area in the field of occupational therapy. Current evidence for using telehealth as a service delivery model within occupational therapy is encouraging but limited, specifically, when it comes to the perspectives and experiences of practitioners providing services through telehealth (Cason, 2014; Dunleavy, Preissner, \& Finlayson, 2013). Cason (2014) reported that several studies have concluded that in some populations and interventions, there are no significant differences between in person OT services and those provided through telehealth. Some populations may even experience better outcomes when provided via telehealth, such as, mental health and substance abuse, home modifications, and cognitive rehabilitation (Cason, 2014). With more comparative studies published that highlight the efficacy of telehealth, there appears to be a common theme in some research studies regarding a lack of practitioner acceptance for the use of telehealth (Cottrell, Hill, O’Leary, Raymer, \& Russell, 2018). Some of the main barriers contributing to the lack of acceptance of 
telehealth include technical difficulties and failures, lack of training, lack of physical contact, and resistance to change (Cottrell et at., 2018; Hiratsuka, Delafield, Starks, Ambrose, \& Mala Mau, 2013; Tucker, 2012a). Hersch, Kao, Melton, \& Pancheri reported that "occupational therapy practitioners reported little telehealth utilization and low self-efficacy with telehealth technology" (2015, p. 1). Their findings suggest the need to "explore the reasons why occupational therapy practitioners may or may not pursue further training” (Hersch et al., $2015 \mathrm{p}$. 1). Using telehealth, occupational therapists are able to deliver services and observe patients in their natural environment and provide immediate feedback individualize to the patient (Cottrell et al., 2018). Faced with the barriers, a lack of acceptance by the practitioner contributes to the poor uptake and sustainability of telehealth (Cottrell et at., 2018). More research must be conducted to determine what factors contribute to the practitioner perspectives of telehealth in order to help foster practitioner acceptance.

The conceptual frameworks that will be the foundation for this study include: The Coaching Model, Person-Environment-Occupation-Performance Model (PEOP), and the United Theory of Acceptance and Use of Technology (UTAUT). First, the Coaching Model is used as a therapeutic tool in occupational therapy to help promote a client-centered practice (Kessler \& Graham, 2014). Specifically, within early intervention (EI), the coaching model is considered the best practice method because it increases parent's efficacy and the participation of the child. When OT services are provided via telehealth, and the coaching model is used as an intervention, an increase in the caregiver-identified goals has been noted, and parents and caregivers have been able to take charge of their own intervention strategies. Caregivers can work with an occupational therapist to develop and implement their own plan and interventions that work within the caregiver and patient's routines (Little, Pope, Wallisch, \& Dunn, 2018). 
The second conceptual framework that will be the foundation for this study is the PersonEnvironment-Occupation-Performance Model (PEOP). The PEOP model focuses on the occupations and performance of the client within their environment (Smith \& Hudson, 2012). The environment is extrinsic in nature and includes cultural, societal, and social interactive factors as well as built environment and technology (Baum, Christiansen, \& Bass-Haugen, 2015; Smith \& Hudson, 2012). Telehealth not only increases access to services, but can also be used to help develops skills, modify different environments (work, home, or school), or help create and establish habits and routines (AOTA, 2018). Telehealth can help connect the occupational therapist to the client's natural, least restrictive environment. With this, the therapist can assess the client's competence level, help develop problem-solving abilities, and promote engagement in naturally occurring occupations in order for clients to help meet their goals within their own natural environment (Cason, 2012a). The PEOP model examines the interconnected relationship between the client's occupations, performance, person, and environment. These four components are interdependent of one another, and the primary concern of this model is identifying what the clients view as their own problems (Baum, Christiansen, \& Bass-Haugen, 2015

The UTAUT is the last framework referenced within the study. It is a newer model (Venkatesh, Morris, Davis, \& Davis, 2003) that was introduced using different constructs of models to help explain technology behavior. This model uses "four basic factors affecting the individual's acceptance and usage of newly encountered technology. These factors are, performance expectancy, effort expectant, social influence and facilitating conditions" (Gücin \& Berk, 2015, p. 1700).

- Performance expectancy means that there is an expected increase of performance. 
- Effort expectancy is the ease-of-use of the technology that is accepted (Gücin \& Berk, 2015).

- Social influence includes the perceptions of self (Gücin \& Berk, 2015).

- Facilitating conditions are the "beliefs about the existence of personal or institutional support encouraging technology acceptance” (Gücin \& Berk, 2015, p. 1700).

Research has shown that one of the main barriers for the successful integration of telehealth into the world of OT is user acceptance (Irfanahemad, Nandakumar, \& Radhiki, 2018). The use of the UTAUT model can help gain a better understanding of the perceived benefits and barriers that OT practitioners have when it comes to the use of telehealth services (Irfanahemad, Nandakumar, \& Radhiki, 2018).

\section{Significance of the Proposed Project}

This project explores the provider's perceptions about the strengths and barriers of OT services provided via telehealth. It may give more insight to practitioners who are hesitant or apprehensive about implementing telehealth and provide information on the benefits and barriers of telehealth. This project can lead the way for future therapists who are interested in telehealth but have limited knowledge with this type of service delivery model. It will be impactful because telehealth is rapidly growing as a service delivery model within occupational therapy (Cason, 2014). With recent changes within the healthcare system, ICT can help expand and increase access of OT services in populations that face barriers on accessing services (Gardner, Bundy \& Dew, 2016).

\section{Project Objectives}

- Participate in observations of telehealth with therapists to determine the focus of the qualitative interview and the survey questions 
- Identify and summarize therapists' perspectives who have experience and who do not have experience with telehealth on the strengths and barriers of providing services via telehealth

- Analyze and draw conclusions from results to suggest further areas of research into use of telehealth

- Provide additional insight and better understanding of positive and negative perspectives that service providers may have when it comes to using telehealth to deliver services

- Determine how to help support practitioners, service providers, and administrators to manage software and technology that is required for telehealth

\section{Definition of Terms}

For the purpose of this proposal, the following terms will be defined as:

Coaching Model: "The emphasis is to coach people to take responsibility for self-direction in naming priorities and goals, which are most meaningful to them. Coaching involves collaboratively identifying challenges, setting goals and working towards the goals sets" (Kessler \& Graham, 2014, p. 1).

Information and Communication Technologies (ICT): "Technologies that provide access to information through telecommunications" (HealthIT.gov, 2017).

Person-Environment-Occupation-Performance Model (PEOP): Client-centered model focused to "improve the everyday performance of necessary and valued occupations of individuals, organizations and populations, and their meaningful participation in the world around them" (Smith \& Hudson, 2012, p. 4).

Occupational Therapy: "Therapeutic use of occupations, including everyday life activities with individuals, groups, populations, or organizations to support participation, performance, and 
function in roles and situations in home, school, workplace, community, and other settings" (AOTA, 2011)

Telehealth: "The application of evaluative, consultative, preventative, and therapeutic services delivered through information and communication technology” (AOTA, 2018, p. 1)

United Theory of Acceptance and Use of Technology (UTAUT): "This model proposes four basic factors affecting the individual's acceptance and usage of newly encountered technology. These factors are, performance expectancy, effort expectant, social influence and facilitating conditions" (Gücin \& Berk, 2015, p. 1700).

\section{Assumptions, Limitations, and Delimitations}

There are four main assumptions of this project. The first assumption is that practitioners are willing and able to participate and share their experiences and perspectives on telehealth. I am also assuming that the practitioners who answer interview questions or survey questions will answer them truthfully and honestly. Before the interview, I will explain how I will keep anonymity and confidentiality to ensure honesty. I am assuming that practitioners and clients will provide consent to observe telehealth sessions. Lastly, I am assuming that practitioners who have never used telehealth have a negative perception or that they have limited knowledge about using telehealth as a service delivery model and that

For this project, there are three main limitations. The first limitation is that I am using a sample of convenience. This means my results may not be generalizable to a different or larger population. The second limitation is scheduling. I have no control over the availability of the providers and the environment the providers may be located during the interview. Lastly, I have no control over how experienced practitioners are who I interview and/or survey and how long they have been using telehealth. 
There are two main delimitations with this study. This first delimitation is the sample population. My study primarily focuses on pediatric and early intervention telehealth sessions and will only explore the perspective of therapists about the use of telehealth within this population setting. Another delimitation is the use of mix-methods research. Surveys and interviews will the primary mode of data collection with this study. The qualitative data will come from the interview questions and some of the survey questions. The quantitative data will come from the survey. I chose mixed-methods research in order to investigate the individual views of therapists who have and have not used telehealth and be able to quantify some of the data results.

\section{CHAPTER II. Literature Review}

Telehealth is an emerging service delivery model that allows the delivery of healthrelated services to clients and patients at a physically different location (World Federation of Occupational Therapists, 2014). This literature review explores the use of telehealth as a service delivery model within occupational therapy as well as other healthcare domains. There have been numerous research articles that report the benefits and barriers of using technology as a service delivery model. However, there is limited research on the perspectives of occupational therapists who use telehealth as a service delivery model (Dunleavy, Preissner, \& Finlayson, 2013). This literature review examines the perspectives of numerous healthcare professionals and their experiences using technology to delivery services. During this literature review, it became clear that the perceptions of using technology did not always align with the experiences of using technology. This perception is important to note because "perceptions can serve as facilitators or barriers to the uptake of new technology and affect adoption of new approaches to care" (Mammen et al., 2018, p. 255) and is critical to the wide-spread implementation (Mammen et al., 
2018). Three themes emerged from this literature review: the use of telehealth as a service delivery model- including the benefits and barriers; positive perspectives on telehealth; and negative perspectives on telehealth.

\section{Use of Telehealth as a Service Delivery Model}

Telehealth is not considered a separate intervention method; instead it is considered a service delivery method used to deliver occupational therapy services (Cason, 2014). Occupational therapy services can be delivered using telehealth with:

- Tele-evaluation by using a variety of reliable assessments

- Tele-intervention to that are preventative, habilitative, or rehabilitative

- Tele-consultation for advice or obtaining health and medical information

- Tele-monitoring for management of chronic diseases or vital signs (AOTA, 2018; Jacobs, Cason, \& McCullough, 2015).

With the use of telehealth, a practitioner can provide services physically distant from the clients (AOTA, 2018). Telehealth can be synchronous or asynchronous. Synchronous is when the services are delivered in real time, while asynchronous is considered "store-and-forward technologies" (AOTA, 2018, p. 1). The AOTA (2018) telehealth position paper research supports the use of telehealth in a variety of areas including consultative services for cognitive screening; orthopedic (hand) assessments; lymphedema assessments; wheelchair prescription; home assessments; adaptive equipment prescription and home modification; ergonomic assessment. Cason (2014) cites additional research that supports the use of telehealth including "wheelchair prescription, neurological assessment, adaptive equipment prescription and home modifications, ergonomic assessment, school-based practice, early intervention services, health and wellness programming, and rehabilitation for individuals who have experienced stroke, breast cancer, 
traumatic brain injury, polytrauma, Parkinson's disease, and other neurological and orthopedic impairments" (p. 29).

Every major practice area within occupational therapy has the potential to use telehealth (AOTA, 2018; Cason 2012b). The major practice areas include children and youth; productive aging; health and wellness; mental health; rehabilitation, disability, and participation; and work and industry (Cason, 2012b). Research has even suggested that telehealth interventions may result in better outcomes with some populations (Cason, 2014). There have been numerous research articles that have examined the benefits and barriers with the use of technology delivered services. In no particular order, the most cited benefits included:

- Improved of access to care, especially for those living in remote or rural areas

- Improved access to specialists or providers

- Reduced travel time

- Shorter wait times to see a specialist and prevention of delays to see a specialist

- Economic savings for patients and a cost-effective tool to provide services

- More personalized care

- Improved care coverage; timeliness of care; and reduced waiting times

- Flexibility in scheduling appointments

- Promotes engagement of occupations in the natural environment

- May promote more engagement and active participation

(AOTA, 2011; Brophy, 2017; Cason, 2012a; Cason, 2012b; Clawson, Selden, Lacks, Deaton, Hall, \& Bach, 2008; Driessen, Castle, \& Handler, 2018; Dunleavy, Preissner, \& Finlayson, 2013; Estes, 2013; Gardner, Bundy, \& Dew, 2016; Meadan \& Daczewitz, 2015; and World Federation of Occupational, 2014). 
Although benefits have been identified, barriers to implementation still exist. In no particular order, the most cited barriers include:

- Financial difficulties including lack of reimbursement, sustained funding, and initial investment required

- Limited technology including infrastructure, interoperability, technology difficulties and challenges

- Apprehension by practitioners and clients

- Practitioners not ready to adopt a new system of technology due to increased workload and need for familiarity and education

- Privacy and security concerns

- State licensure issues

- The need of more rigorous research to help support the use of telehealth

- Issues of scheduling and needing to go to a separate location from the primary office (Brophy, 2017; Cason, 2012a; Cason, 2012b, Clawson et al., 2008; Cottrell et al., 2018; and Dunleavy, Preissner, \& Finlayson, 2013).

\section{Positive Perspectives After Use of Telehealth}

The perceptions of telehealth do not always align with the experiences of telehealth. Cottrell et al. (2018) reported that the perceptions and acceptance of telerehabilitation increased over time throughout the early implementation phase of the service. In addition, Acharya \& Rai (2016) reported that all doctors treating patients through telemedicine reported high satisfaction with the quality of the treatment, and the majority were willing to promote the use of telemedicine. It should be pointed out that the positive perspectives often align with the benefits of telehealth. However, it is critical to understand the perspectives of practitioners in order to 
understand the factors that facilitate acceptance and satisfaction that practitioners have when it comes to the use of telehealth (Cottrell et al., 2018). After using technology as a service delivery model, research indicated that the positive perspectives on technology use included:

- Having previous experience with telehealth

- Being a younger age

- Having training and familiarity with technology

- Improved quality of care

- $\quad$ Easier access to specialists

- Reduced travel time and shorter wait times

- Economic savings- cost effective medium

- Significantly greater number of visits and more minutes of intervention when compared to in-person sessions

- Patients were able to access care in their home

- Easier to manage readmissions

- Improved timeliness of care

(Archarya \& Rai, 2016; Behl, Blaiser, Cook, Barrett, Callow-Heusser, Moog Brooks, Dawson, Quigley, \& White, 2017; Cottrell et al., 2018; Driessen, Castle, \& Handler, 2018; Hiratsuka, Delafield, Starks, Ambrose, \& Mala Mau, 2013; Lincoln, Hines, Fairweather, Ramsden, \& Martinovich, 2014; Richards, King, Reid, Selvaraj, McNicol, Brebner, \& Godden, 2005; Serwe, 2018; and Tucker, 2012b).

\section{Negative Perspectives After Use of Telehealth}

Telehealth as a service delivery model also faces some negative perspectives. Lincoln, Hines, Fairweather, Ramsden, \& Martinovich (2014) reported that therapists often have more 
negative attitudes toward teletherapy than stakeholders, which could attribute to the lack of willingness to adopt the technology. It is important to identify the negative perspectives on the use of technology in order to highlight the perceived barriers when it comes to the widespread uptake of technology services (Richards et al., 2005). It should be pointed out that the negative perspectives often align with the barriers of telehealth. Some of the most common negative perceptions of technology-based services include:

- Concerns of increased workload, client safety, decrease quality of care, costs, and establishing therapeutic relationships

- Technology issues and failures including communication lapse or delay, poor connection (audio and/or visual), suboptimal image clarity, lack of reliable technology

- Not having technical support when technology fails

- Limited internet access, especially in rural areas

- Initial investment- costly investment in the equipment

- Cost to maintain and sustain equipment

- Concerns regarding confidentiality

- Lack of staff educated in information technology- difficulties in learning and using

- Lack of practitioner acceptance due to resistance to change, poor technology selfefficacy, and uncertainty about telehealth

- Lack of resources and support

- Concerns related to the patient-clinician therapeutic relationship

- Being 'old fashioned' and lack of physical contact

- Lack of research

- Dissatisfaction 
(Archarya \& Rai, 2016; Cottrell et al., 2018; Driessen, Castle, \& Handler, 2018; Dunkley, Pattie, Wilson, and McAllister, 2010; Hiratsuka et al., 2013; Kandola, Banner, Araki, Bates, Hadi, \& Lear, 2018; Lincoln, Hines, Fairweather, Ramsden, \& Martinovich, 2014; Mammen et al., 2018; Odeh, Kayyali, Gebara, \& Philip, 2014; Richards et al., 2005; Serwe, 2018; and Tucker, 2012b). Telehealth is an underused resource that can be beneficial to patients and clients in a variety of populations (Nobakht, Rassafiani, Hosseini, \&Ahmadi, 2017). There is limited research on the perspectives of occupational therapists who use telehealth as a service delivery model (Dunleavy, Preissner, \& Finlayson, 2013) and it is important to understand those perspectives in because they will be the facilitators or barriers to the widespread implementation to telehealth services (Mammen et al., 2018).

\section{CHAPTER III. Project Description}

\section{Planned Design, Materials, and Participants}

This is a mixed-methods study that will use qualitative data from the interview questions and some of the survey questions and quantitative data from the majority of the survey questions to collect data on the use of telehealth as a service delivery model. A mixed-methods study is used for this project because it allows for the comparison between qualitative data and quantitative data. It will be useful to compare the two data sets in order to understand if there are any contradictions between the results (Wisdom \& Creswell, 2013). The qualitative data will be used to describe the characteristics of the results while the quantitative data will be used to quantify the results (Research Guides, 2019). Based off of the literature review, it became evident that there is a discrepancy between the perspectives of telehealth and the experiences with telehealth. A mixed-method study will reflect the point of view of the participants (Wisdom 
\& Creswell, 2013). For the purposes of this study, the point of view will be from the service providers' perspectives and experiences with telehealth.

The project will be completed at HM Systems, Inc in Carlsbad, CA and Pediatric Therapy Network (PTN) in Torrance, CA. The majority of the hours during HM Systems will be completed in-person and will involve observation of therapy sessions and interviewing practitioners. The interview of service providers will occur in between patient sessions or after hours in person or virtually. HM Systems wants to implement a telehealth program, but they are facing barriers on the adoption process. It is expected that the majority of these interviews will be service providers who have limited experience using telehealth. This time at HM Systems will allow for a better understanding on the delivery of EI services as well as service providers perspectives on telehealth sessions delivered via telehealth. PTN offers telehealth service in occupational therapy, physical therapy, and speech therapy, and will provide opportunities to observe telehealth sessions. The hours at PTN will consist of observing telehealth sessions inperson and virtually, as well as conducting interviews of therapists who have experience with telehealth. The desired number of service providers to interview between both sites is twenty, with an even distribution of service providers who have experience with telehealth and those who have little to no experience.

The interviewees will consist of participants recruited with convenience sampling from service providers at HM Systems, PTN, and volunteer service providers willing to participate from online telehealth forums. The interviews will take 30-45 minutes to complete. They will consist of semi-structured, open-ended questions, allowing opportunities for follow-up questions. The interviews will be recorded using a personal recording device where the audio can be deleted right after the transcription process. Confidentiality will be maintained at all times and no 
names will appear on the audio recordings. If a service provider does not want to be recorded, then the interview will still take place, but will not be used as part of the data. The recorded interviews will be transcribed, analyzed, and coded. In addition, posts will be published on various telehealth forums asking for volunteers and participants for either partaking in the interview or survey. The post will include links to two voluntary surveys - one survey will be for service providers who have used telehealth and the other will be for service providers who have never used telehealth. The desired number of participants to complete the survey will be fifty and at least ten service providers will volunteer to be interviewed. The survey will consist of openended and closed-ended questions that parallel the interview questions. The survey will provide both qualitative and quantitative data sets in order to help validate and provide stronger support to the interview questions. In order to conduct this study and for the results to be used in future studies, a request for approval by the Institutional Review Board (IRB) of St. Augustine for Health Sciences has been submitted and approved.

The purpose of this mixed-methods design is to gain a better understanding of the provider's perspectives about the strengths and barriers of OT services provided via telehealth. The acceptance and success of using telehealth as a service delivery model is based off of the attitudes and perceptions service providers have towards its use (Dunkley, Pattie, Wilson, \& McAllister, 2010). The information collected through surveys and interviews can help determine specific factors regarding whether or not therapist choose to provide services through telehealth as well as the concerns and issues therapists have when it comes to using telehealth.

\section{Planned Timeline and Procedure}

The first four weeks of the project (July 29, 2019 to August 23, 2019) will consist of observing EI sessions at HM Systems and telehealth sessions at PTN. Participating in these 
observations will help gain an understanding of EI occupational therapy services and telehealth sessions. In addition, these observations will help guide and determine the focus of the interview questions and surveys of service providers. During this time, the interview questions

(Appendices A and B) and surveys (Appendices C and D) will be finalized. Once finalized, interviews can begin, and the survey can be sent out to various telehealth forums (Appendix E for self- introduction).

Beginning of September 2019, practitioners will continue to be interviewed and the survey will be posted again. By October 2019, the majority of the practitioners will be interviewed, and the data analysis will begin. During this time, all the transcripts from the interviews will be transcribed and coded in order to analyze and draw conclusions from the interview results. Participants will have a chance to complete the survey until the end of October. Once the survey is closed, the data will be analyzed in order to determine findings from the survey results. It is expected, starting in November 2019, that the results of the interview and survey will be transcribed and analyzed. The analysis will take place in two steps. In the first step, the results will be separated based on the discipline of the service provider. This allows an analysis of the results to just focus on occupational therapy practitioner perspectives. The second step of the analysis involves combining the results of each discipline. Based on the result analysis, conclusions suggest further areas of research or program development into use of telehealth. In addition, the results will help determine how to support practitioner, service providers, and administrators to manage software and technology that is required for telehealth. With HM Systems facing barriers on telehealth implementation, a presentation of the results will be completed in late November or early December. 


\section{Actual Methods and Timeline}

Due to scheduling and availability of therapists for observations, the timeline of the project was altered. Instead of observations, the first four weeks of the capstone experience were centered around: completing the required Institutional Review Board (IRB) forms and documents and getting IRB approval from the University of St, Augustine; finalizing the survey and interview questions, including conducting mock interviews; continue researching and expanding knowledge on telehealth, which included, but was not limited to research on privacy and security, program development, and legislation; and began telehealth observations with an outpatient treatment center, Lasting Recovery.

The observations started at the beginning of September 2019 with HM Systems and PTN. Observations of the EI therapists (occupational therapists, physical therapists, and speech therapists) at HM Systems were conducted until the end of September. The observations helped gain a better understanding of EI and helped understand the day-to-day schedules of an EI therapists. The time also allowed for building rapport with the therapists and to casually discuss telehealth and their perspectives on its use. Once the observations were completed at HM Systems, the surveys were posted to online telehealth forms. Along with the survey, the forum posts also asked for volunteers who were interested in being interviewed (appendix E). Participants had the chance to complete the survey until the end of October. All of the interviews also took place in October and the majority of the interviews were completed over the phone or via Zoom. During this time, the transcription process also began.

Starting in the beginning of November, all of the interviews were completed, the surveys closed, and the data analysis began. Also during this time, telehealth observations were still being completed. The observations included an occupational therapist with PTN, an occupational 
therapist with Lasting Recovery, and an EI occupational therapist based in Colorado. The methods of the data analysis were slightly altered due to the majority of the participants being occupational therapists.

The data was analyzed using thematic analysis and compare and contrast charts. Thematic analysis allows "the researcher to see and make sense of collective or shared meanings and experiences" (Braun \& Clark, 2012, p. 57) and to be able to form a "pattern [of] recognition within the data, where emerging themes become the categories for analysis" (Fereday \& MuirCochrane, 2006, p. 82). The compare and contrast charts (Table 1 and Table 2) provide a summary of the benefits and barriers of using telehealth services based on the perspectives and experience of service providers who have experience with telehealth and who do not have experience with telehealth. After completion of the data analysis, a presentation was given to the San Diego Regional Center (Appendix F) and to the staff at HM Systems (Appendix G) on the findings from this project with the intent to support the establishment of a telehealth program for early intervention.

\section{CHAPTER IV. Analysis and Results}

\section{Data Analysis}

The data analysis consisted of multiple parts. The interviews and surveys were analyzed independently and then then merged for the final results. First, the audio recorded interviews were transcribed verbatim. Then, the interview transcripts were divided into two groups-service providers who have telehealth experience and service providers with no telehealth experience. The interview transcripts were analyzed and coded first. After that, the analysis consisted of two parts - the six-phase approach to thematic analysis (Braun \& Clark, 2012) and creating compare and contrast charts of the benefits and barriers separated by group. The first phase of thematic 
analysis involved becoming familiar with the data. Each transcript was thoroughly read and general notes about the data were written in a notebook. Phase two consisted of generating initial themes. The transcripts were then re-read, and codes were used to "identify and provide a label for a feature of the data that is potentially relevant to the research question" (Braun \& Clark, 2012, p. 61). Phase three of the thematic analysis involved searching for themes. This was when all the codes were reviewed together, and areas of similarity and overlap were identified. Phase four consisted of reviewing the potential themes, phase five involved defining and naming themes, and phase six involved the write-up of the results. Once the interview transcripts were fully analyzed, the survey results were analyzed using similar analysis process as the transcripts. Once the survey and interviews were fully coded and themes were identified and defined, the results were merged and collated. After the thematic analysis took place, the compare and contrast charts were completed based on the results from the survey and coded transcripts.

\section{Results}

Results from the data are represented based on whether participants had experience using telehealth (Figure 1.1, 1.2, 1.3, 1.4 and 1.5) and had no experience using telehealth (Figure 2.1, 2.2, 2.3, and 2.4), the most frequently reported benefits and barriers of telehealth services (Table 1 and 2), and the responses from the interviews and survey grouped into the four major themes (Table 3). The results from the interviews and survey from the two groups were compared in order to gain a better understanding of how the perspectives of participants with experience with telehealth compared to the perspectives of those who did not have experience with telehealth.

Participants. The total number of responses include 46 service providers - 31 service providers responded to the online surveys and 15 service providers were interviewed. The service providers were divided into two groups - service providers with telehealth experience 
(group 1) and service providers with no telehealth experience (group 2). Specific questions were asked in both the survey and the interviews to gain a better understanding of certain characteristics of the participants on a professional level.

Group 1: Service providers with telehealth experience. In group one, responses from the online survey were submitted by nine service providers and seven service providers were interviewed, for a total of sixteen service providers who have used telehealth. Specific questions asked about the service provider are listed below.

\section{Question: Please indicate your discipline.}

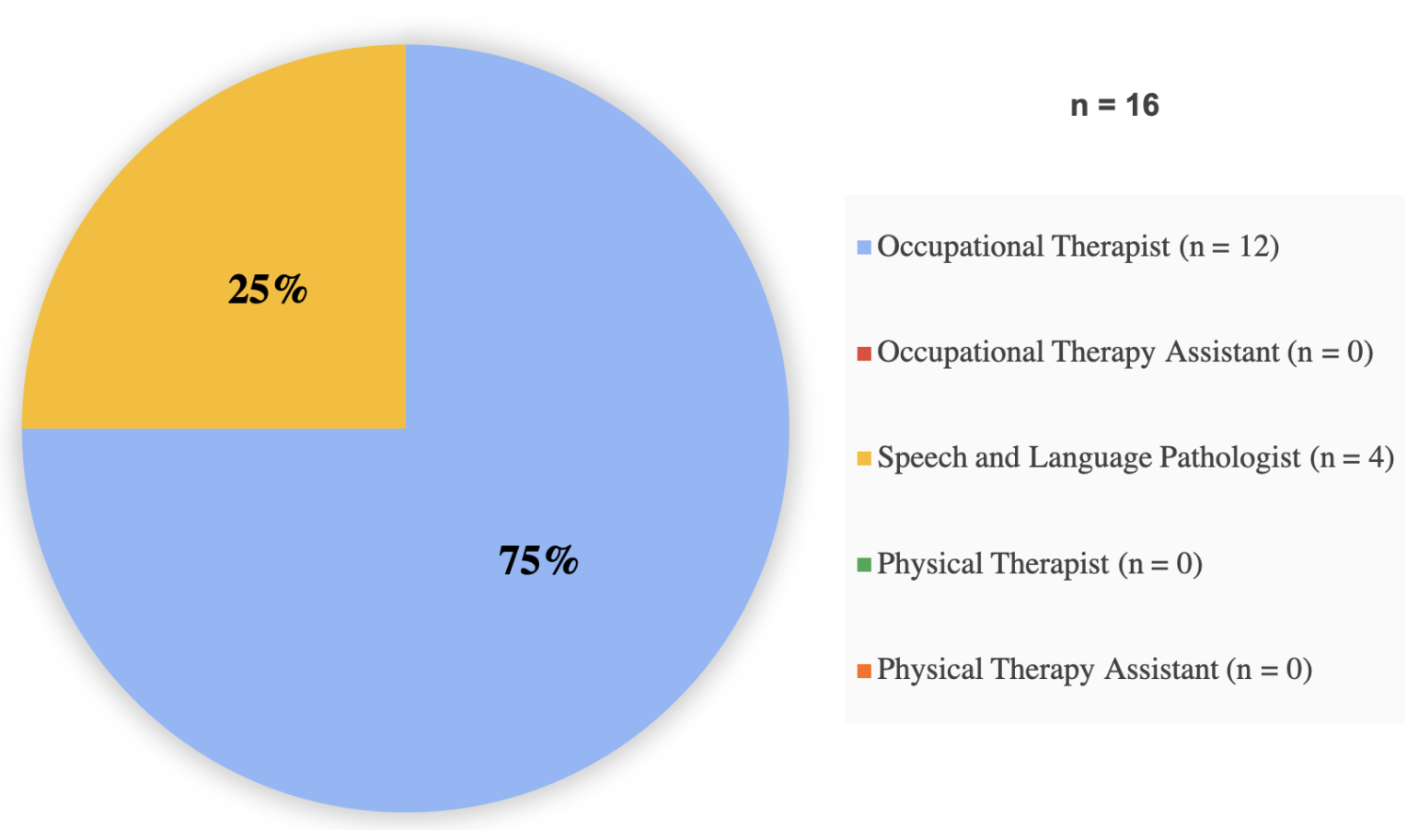

Figure 1.1. Total number of service providers who have telehealth experience based on discipline 
Question: How long have you been working as the service provider you selected in the question above?

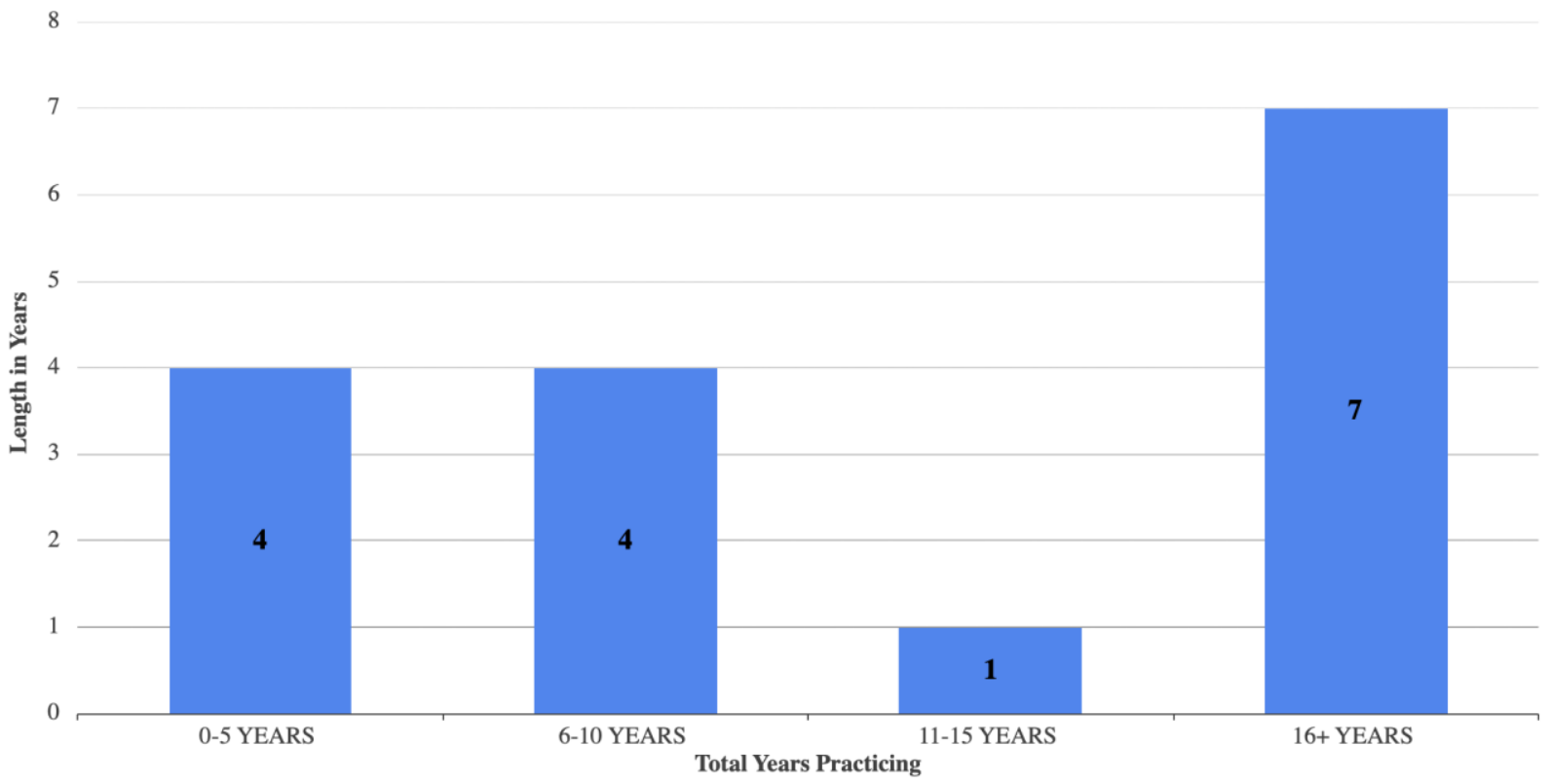

Figure 1.2. Total number of service providers who have telehealth experience based on years practicing 


\section{Question: How long have you been using telehealth to provide services?}

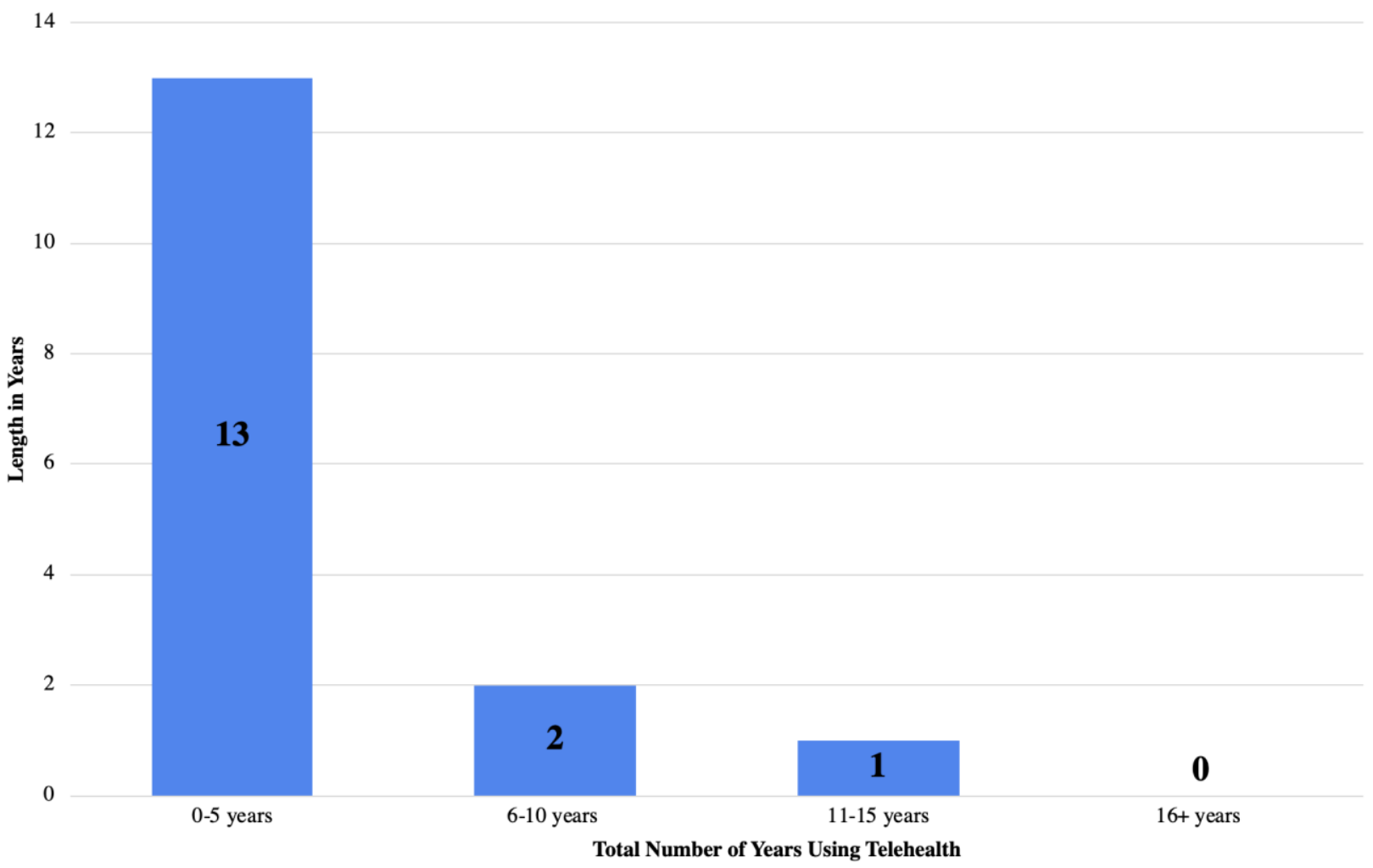

Figure 1.3. Total number of service providers who have telehealth experience based on the number of years using telehealth 


\section{Question: What population(s) do you primarily work with?}

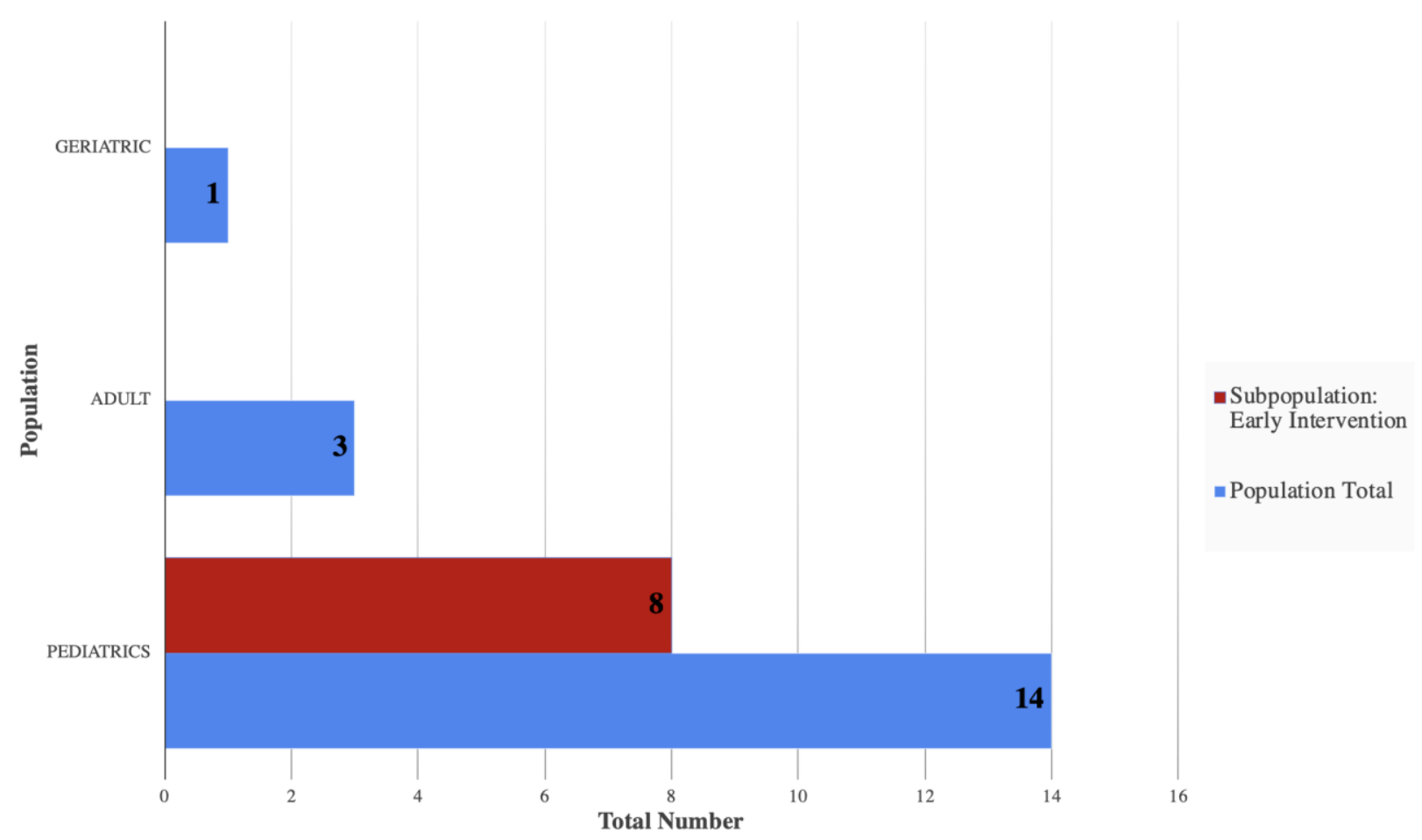

Figure 1.4. Total number of service providers who have telehealth experience based on the primary population(s) they work with. Note. Two of the service providers interviewed and surveyed worked with more than one population and eight of the service providers work in early intervention. 
Question: Telehealth is used for which percentage of your clients?

7

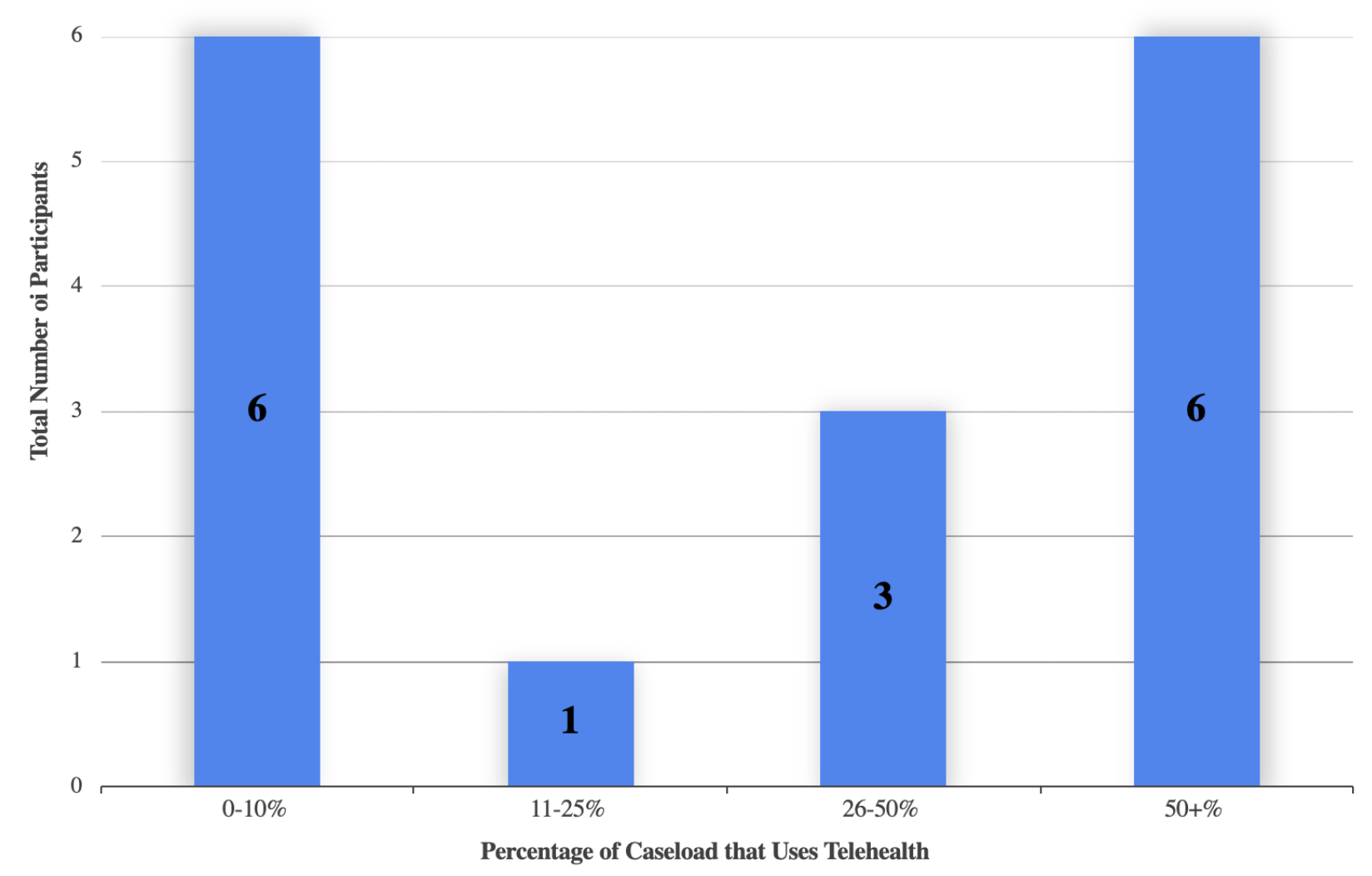

Figure 1.5. Total percentage of service provider's caseload that are provided using telehealth 
Some addition items that are important to note are:

- $100 \%$ of the service providers reported that they 'like using [telehealth]' as a service delivery model, but many noted that telehealth is not an 'one size fits all' type of delivery method

- Four out of sixteen (25\%) service providers reported that they use telehealth for $100 \%$ of their caseload

- Over $80 \%$ of the service providers reported that clients seen via telehealth should make about the same or more progress when compared to clients seen in person.

○ One participant reported: "I think that if you are using telehealth appropriately and correctly, the same progress is made. "-Speech Language Pathologist

- Another participant reported: "I find the progress comparable or greater to onesite, as services are 1:1 and students/learning coaches take ownership in their program. "-Speech Language Pathologist

- The most cited responses for when service providers purposefully choose to use telehealth include (does not consider the number of service providers who use telehealth for $100 \%$ of their caseload):

○ Makeup session (58\%)

○ Child/Family Illness (58\%)

○ Providers illness $(50 \%)$

○ Reduced travel time $(50 \%)$

- Providing services in a different state (37\%) (includes service providers who use telehealth $100 \%$ of the time)

○ Client/parent request (33\%) 
○ Transportation $(33 \%)$

Inclement weather $(25 \%)$

- Help with transitioning skills from clinic to home (25\%)

○ “Off” hours $(16 \%)$

- Service providers who participated in the survey were asked when they thought service providers would have a more positive perspective about telehealth. The reasons include:

○ Having previous experience with telehealth (100\%)

○ Having training and familiarity with the technology $(89 \%)$

- When telehealth improves the timeliness of care $(56 \%)$

- When it reduces the amount of time a therapist has to travel (44\%) 
Group 2: Service providers with no telehealth experience. In group two, responses from the online survey were submitted by twenty-two service providers and eight service providers who have not used telehealth were interviewed, for a total of thirty participants with no telehealth experience. Specific questions asked about the service provider are listed below.

\section{Question: Please indicate your discipline.}
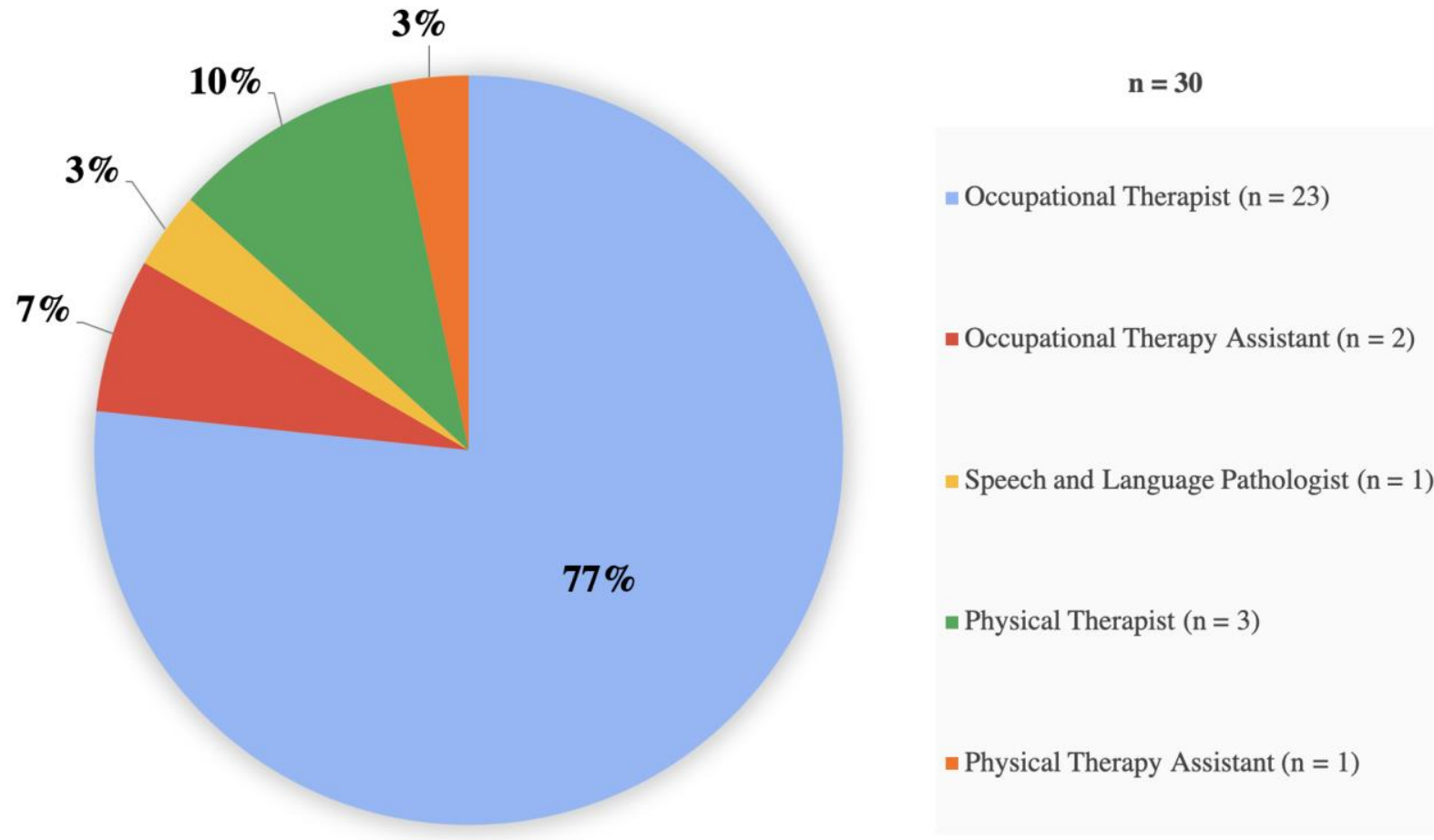

Figure 2.1. Total number of service providers who have no telehealth experience based on discipline 
Question: How long have you been working as the service provider that you answered in the question above?

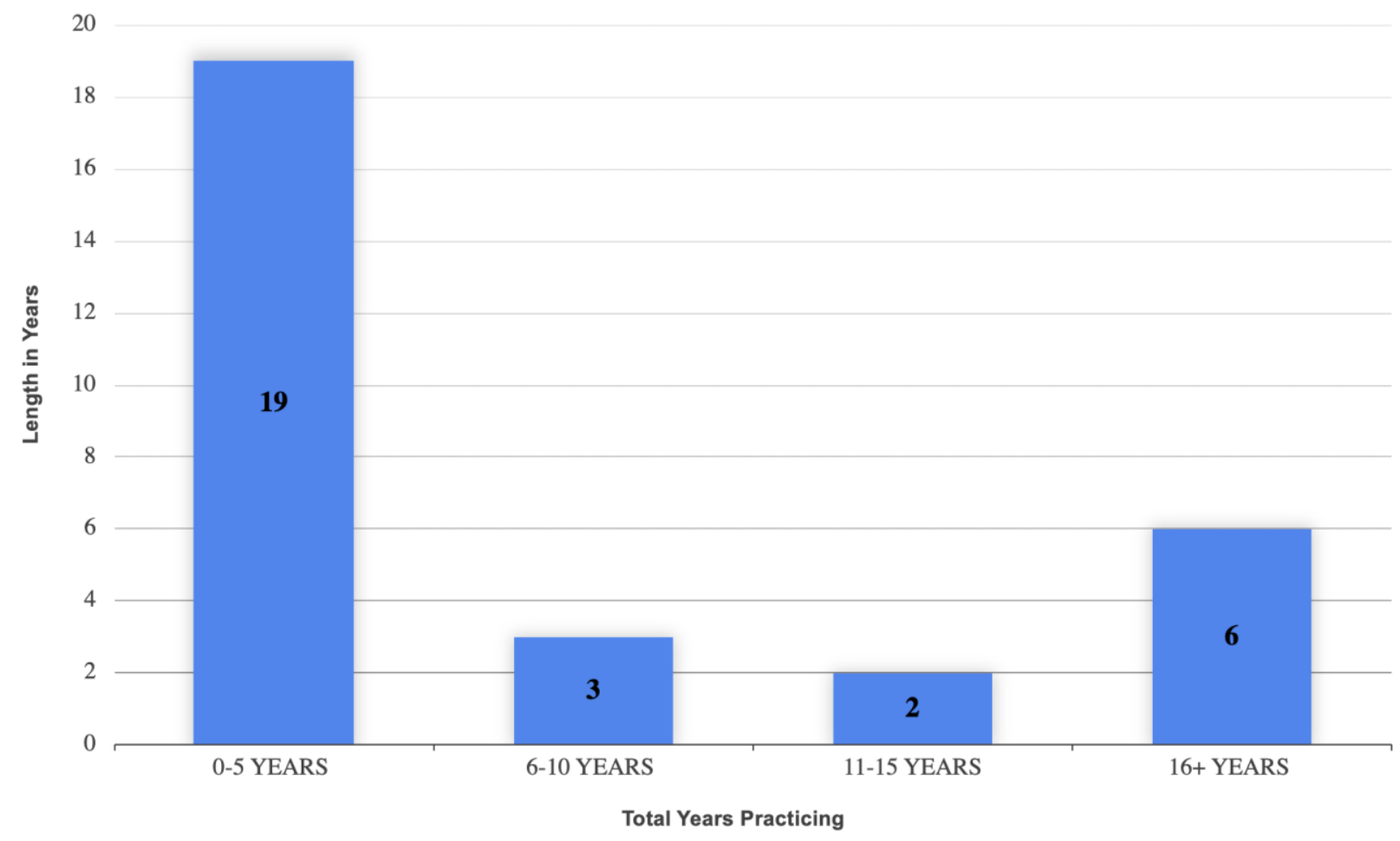

Figure 2.2. Total number of service providers have no telehealth experience based on years practicing 


\section{Question: What population(s) do you primarily work with?}

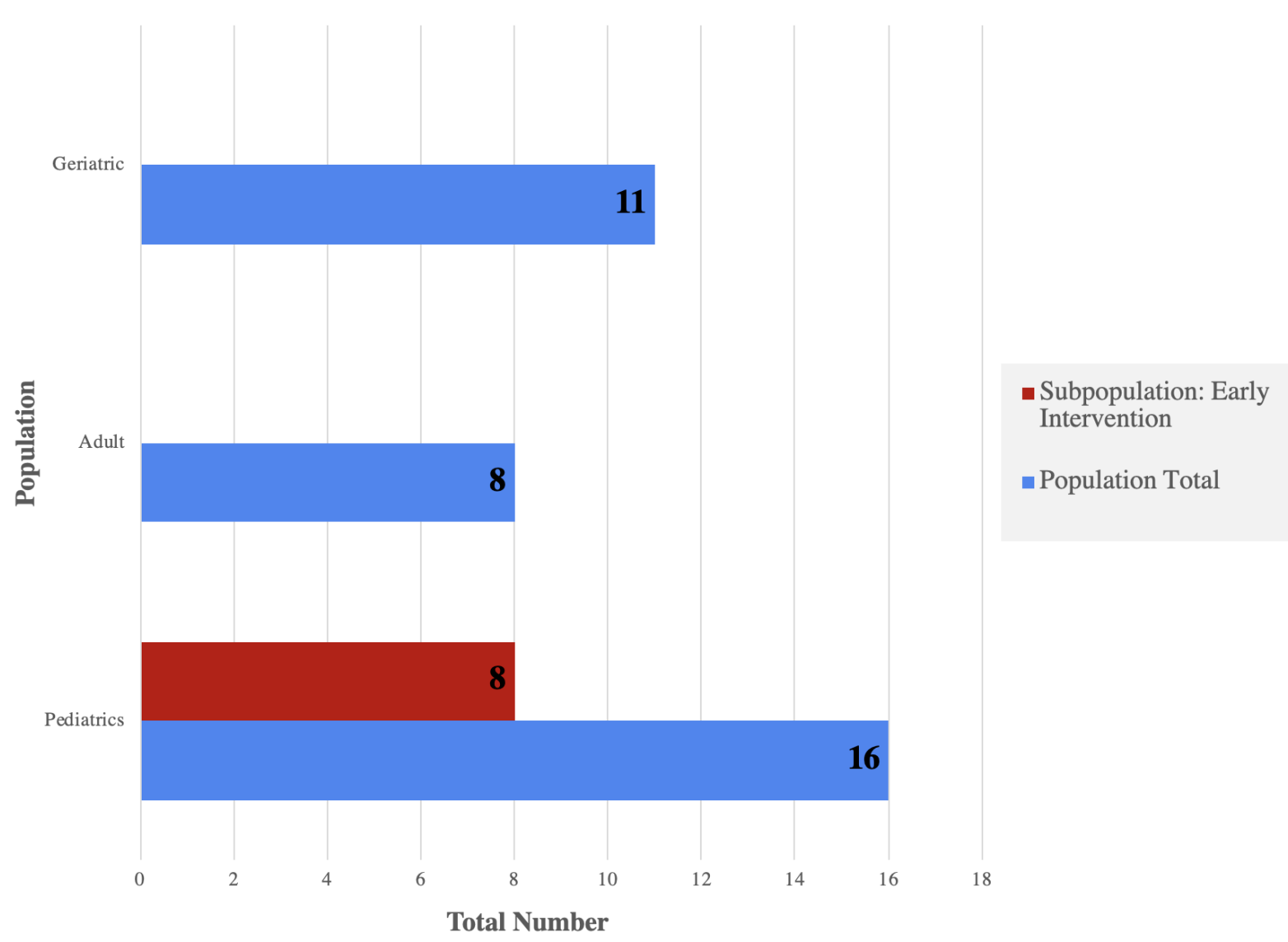

Figure 2.3. Total number of service providers who have no telehealth experience based on the primary population(s) they work with. Note. Six of the service providers interviewed and surveyed worked with more than one population and eight of the service providers work in early intervention. 


\section{Question: Are you interested in using telehealth?}

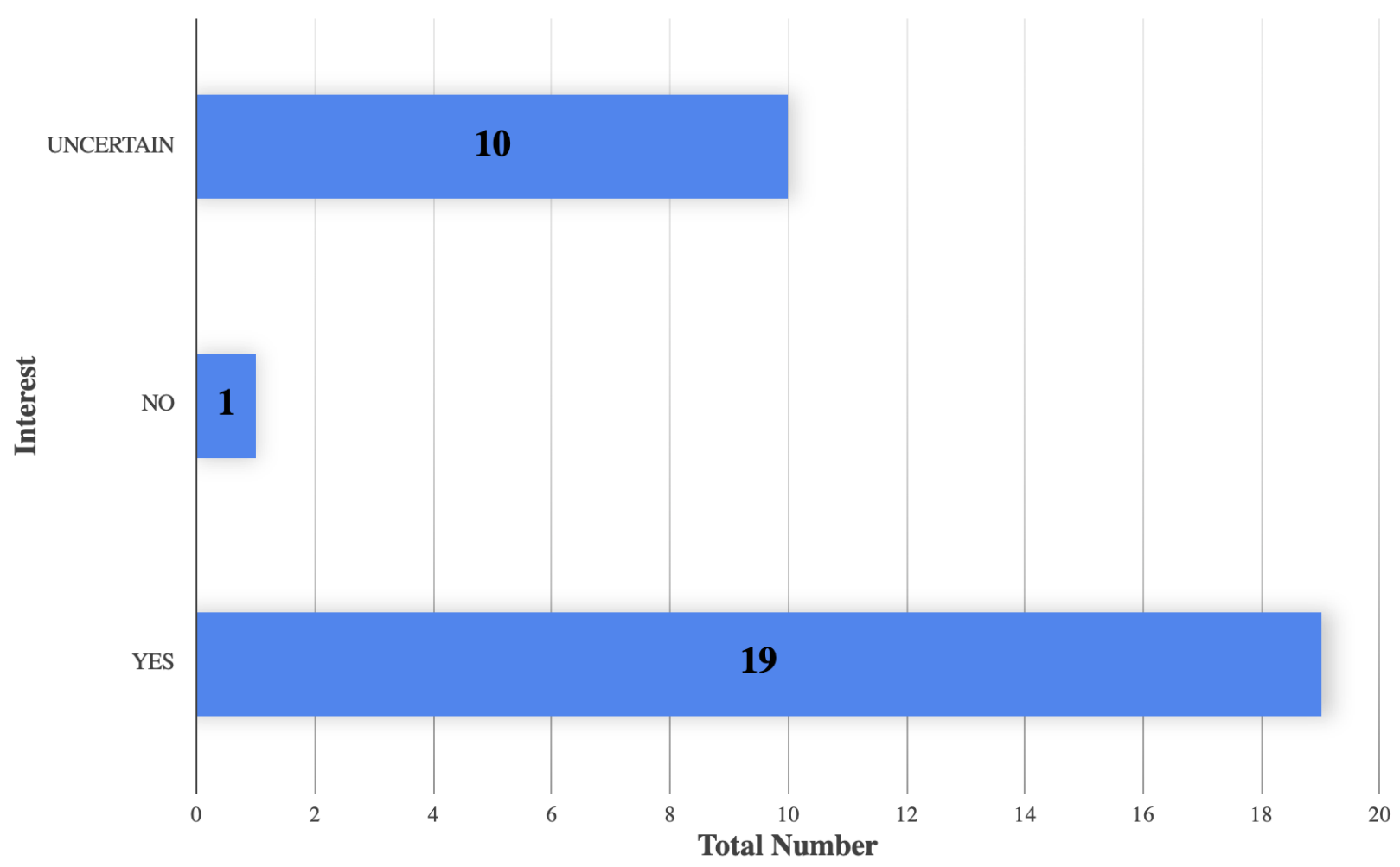

Figure 2.4. Total number of service providers who have no telehealth experience based on their interested in using telehealth

When asked why they haven't used telehealth yet, one of the participants reported:

"I don't know how to get involved or even where to start. I also would want more experience with OT before using telehealth. I am also not confident on coaching parents and treating children through the screen. I would like more years of experience before using telehealth."-Occupation Therapist 
Some addition items that are important to note are:

- When asked about whether or not telehealth was taught during school, participants reported:

- “We kind of learned about it, but nothing too in-depth. I couldn't even tell you what class mentioned it. "-Occupational Therapist

- 'Yea, we talked about it a little bit, but I wouldn't say we went into much depth."-Occupational Therapist Participant

- During the interview, when participants were asked why they think people are apprehensive about using telehealth, five out of eight (63\%) of the participants explicitly noted that they themselves are apprehensive about using telehealth. Some of the participants reported:

○ 'Once therapists have a routine of how they do things and it's a system that works well. You are reluctant to change."-Occupational Therapist

- "I agree. Just because I think it's smart to assess the pros and cons of things, and I can already see some apprehensions that I would specifically have, so I think it's good that other people are at least aware of those as well."-Occupational Therapist

- "I am apprehensive as I find it easier to have in person conversations so I can use language and hands on techniques to ensure full comprehension. However, I also feel that maximizing services and availability of services to people is beneficial. "-Physical Therapist

○ “I agree. I think I am one of those people."-Occupational Therapist 
Benefits and barriers. Every participant from the interviews and survey were asked the same two questions: what do you think are the benefits of using telehealth services and what do you think are the barriers. Table 1 and Table 2 summarize the most frequently reported benefits (Table 1) and barriers (Table 2) of using telehealth services based on the experience of service providers who use telehealth and the perspectives of service providers who have not used telehealth.

Table 1.

Most Reported Benefits of Using Telehealth as a Service Delivery Model

\section{Most Reported Benefits}

\section{Responses from Service Providers who $\quad$ Responses from Service Providers who Have Used Telehealth $(n=16) \quad$ Have Not Used Telehealth $(n=30)$}

1. Improve accessibility of services/care $(88 \%)$

2. Flexibility in scheduling appointments $(69 \%)$

3. May promote more engagement and active participation by the client/caregiver (63\%)

4. Reduce travel time $(63 \%)$

5. Prevention of delays to see a specialist $(38 \%)$

6. A cost-effective tool for providing services $(38 \%)$

7. Helps with transitions within the home environment (24\%)

8. Mitigate cancellations (19\%)
1. Improve accessibility of services/care (87\%)

2. Flexibility in scheduling appointments (77\%)

3. Reduced travel time (70\%)

4. Prevention of delays to see a specialist (60\%)

5. A cost-effective tool for providing services (37\%)

6. May promote more engagement and active participation by the client/caregiver (37\%)

7. Tool for referrals, consultations, and screens $(16 \%)$ 
Table 2.

Most Reported Barriers of Using Telehealth as a Service Delivery Model

\section{Most Reported Barriers}

\section{Responses from Service Providers who $\quad$ Responses from Service Providers who Have Used Telehealth $(n=16) \quad$ Have Not Used Telehealth $(n=30)$}

1. Apprehension by practitioners and clients $(88 \%)$

2. Limited technology including infrastructure, interoperability, technology difficulties and challenges $(81 \%)$

3. Practitioners not ready to adopt a new system of technology due to need for familiarity $(63 \%)$

4. Financial difficulties including lack of reimbursement, sustained funding, and/or initial investment required (44\%)

5. State licensure issues $(19 \%)$

6. The need of more rigorous research to help support the use of telehealth $(13 \%)$

7. Lack of regulations to monitor telehealth (13\%)

8. Isolation from other therapists (13\%)

1. Lack of physical contact (93\%)

2. Concerns of decreased quality of care (90\%)

3. Apprehension by practitioners and clients $(87 \%)$

4. Limited technology including infrastructure, interoperability, technology difficulties and challenges (70\%)

5. Lack of ability to establish therapeutic relationships $(67 \%)$

6. Lack of rigorous research in support of the use of telehealth (53\%)

7. Financial difficulties including lack of reimbursement, sustained funding, and/or initial investment required (40\%)

8. Practitioners not ready to adopt a new system of technology due to uncertainty and need for familiarity (37\%)

9. Privacy and security concerns (37\%)

The participants who have experience with telehealth reported that the number one barrier of telehealth is the apprehension by practitioners and clients. One participant reported that "It's the therapist buy-in we have a hard time with, more than the parents. I think parents will try it if the therapist is selling it well. It's the therapists that are scared to use the technology themselves. "-Occupational Therapist 
Service providers who have experience with telehealth reported that they think service providers are apprehensive to use telehealth due to:

- Concerns involving technology issues and failures including communication lapse or delay, poor connection (audio and/or visual), suboptimal image clarity, lack of reliable technology $(75 \%)$

- Concerns of establishing therapeutic relationships (69\%)

- $\quad$ Lack of physical contact $(69 \%)$

- Concerns of decreased quality of care $(63 \%)$

- Lack of practitioner acceptance due to uncertainty about telehealth (44\%)

- One provider noted, “You know, so it's people, I guess [who] don't have an open perception or open mind to how we can do OT online."-Occupational Therapist The most reported reasons for apprehension from service providers with no telehealth experience include:

- Lack of physical contact (93\%)

- Concerns of decrease quality of care $(90 \%)$

- Concerns of establishing therapeutic relationships (67\%)

- Concerns involving technology issues and failures including communication lapse or delay, poor connection (audio and/or visual), suboptimal image clarity, lack of reliable technology $(63 \%)$

- Lack of practitioner acceptance due to uncertainty about telehealth (37\%) 
Themes. From the results, four major themes were identified from the collation of the interviews and surveys.

Table 3.

Definition of the major themes that were identified from the interview and survey results

\section{Major Themes}

\begin{tabular}{|l|l|}
\hline Theme Name & Definition* \\
\hline Accessibility & $\begin{array}{l}\text { Any comment that mentioned increase access to services or service } \\
\text { providers }\end{array}$ \\
\hline Efficacy & $\begin{array}{l}\text { Comments that compare telehealth to in-person sessions and how } \\
\text { well it works. }\end{array}$ \\
\hline Flexibility & $\begin{array}{l}\text { Any comment that reports using flexibility as a reason for using } \\
\text { telehealth. }\end{array}$ \\
\hline Technology & $\begin{array}{l}\text { Comments that mentions technology (i.e: internet connection) in } \\
\text { reference to telehealth. }\end{array}$ \\
\hline \multicolumn{2}{|l}{ Note. The definitions were derived from the definitions reported in Cole, Pickard, \& Stredler- } \\
Brown (2019).
\end{tabular}

Accessibility. When asked about the benefits of using telehealth to provide services, accessibility of services/care was the most reported benefit and prevalent theme for both service providers who have used telehealth $(88 \%)$ and those that have not used it $(87 \%)$. Telehealth allows an increase of accessibility of services/care that may have otherwise been limited due to service provider shortages, geographic limitations of clients, inclement weather, transportation issues, or immunocompromised clients just to name a few. One participant reported,

"I think the number one benefit is we're able to increase accessibility of services to others, especially those that are in underserved areas, whether it's geographical reasons or socioeconomic or whatever it is. "-Occupational Therapist. 
Another service provider who had not used telehealth reported that they could see the benefit in using telehealth,

"Especially [for] the more rural families where I've had trouble saying no in the past and I've gone out of my way for those kiddos, when they [Regional Center] can't find a therapist to go out and see them... I know for me, I've had to turn down families, that maybe telehealth would have allowed me to work with them if I had it available to me and to them... So, if I'm able to provide my expertise and my training to them and this is the best option to do it versus having nothing, then I'm open to definitely exploring telehealth, especially in those instances"-Occupational Therapist.

Flexibility. Flexibility was the second most recorded benefit and prevalent theme for both service providers who have used telehealth (69\%) and those that have not used it $(77 \%)$. When talking about cancellations due to illness or last-minute changes, one participant with experience with telehealth reported,

"I think it is a good backup. I have more flexibility. And especially for those last-minute cancellations where the family still wants to talk to you.... [it] really adds some stability”-Speech and Language Pathologist.

Another reported,

"I absolutely love providing services with telehealth. 100\% of my caseload is telehealth and it allows me to be semi-retired, but still practice part time."-Occupational Therapist

When talking about the benefits of telehealth, one participant who has not used telehealth reported, 
"I also think that telehealth would be beneficial for when it comes to home routines and therapy in the home environment... It adds the flexibility of scheduling where I wouldn't mind providing a session at night, especially if it's a nighttime routine or something like that, where I can be at my home providing the services."-Occupational Therapist.

Using telehealth increases the flexibility for service providers and allows them to be more in control of their schedules and when they provide service.

Efficacy. When asked about the barriers of telehealth services the 'lack of physical contact' was the most reported barrier by service providers who have not used telehealth (93\%). This barrier was used as a category and fell under the theme of efficacy. One service provider who did not have experience with telehealth reported uncertainty about using telehealth due to the lack of physical contact since,

"Parents often have difficulty grasping the concept of handling and positioning techniques and require hand over hand and in person demonstration to allow for improved comprehension and skill acquisition"-Physical Therapist.

However, this barrier was not highly reported by service providers who have used telehealth. One service provider who uses telehealth explained this trend by saying, "It's because it's an emerging area for professionals, so not everyone understands what online sessions entail. And not everyone understands that therapy doesn't mean having your hands on a patient throughout the whole session."-Occupational Therapist Additionally, many of the service providers who use telehealth reported that they use a hybrid type model where they still see their clients in person, but also with telehealth. Due to the participants' high frequency use of the hybrid model, the service providers who used telehealth did not report 'lack of physical contact' as a barrier. The premise of 'lack of physical contact' 
only came up when a service provider was asked about what they like least about telehealth, they reported,

"I miss being in the same room as the families, but overall I am just very positive about it [telehealth]. I asked one of my therapists, 'Don't you miss, like being able to touch the kids and being able to get hugs?' [The therapist] said, 'Well actually a student just brought in his stuff bear up to the computer monitor and gave me a big hug via the computer.' Like, they're still developing those relationships. "-Occupational Therapist Technology. For the participants who had used telehealth, 'limited technology' was the second most prevalent barrier. However, it should be noted that over $90 \%$ of the participants reported that the technology works "at least $90 \%$ of the time" and that technological failures "rarely happens"-Occupational Therapist. Providers who reported technology as a barrier of telehealth went on to explain their experiences with technology:

- 'Sometimes the internet can cut off or restart. So sometimes we'll have a link in the zoom meeting and then it can say poor connection, or all sudden someone drops out of their room. And that's because either the internet cut off or there was an electricity glitch. Sometimes it just freezes for whatever reason, the battery dies, but it's really adjustable and fixable."-Occupational Therapist

- "I have had a couple technological glitches, but never full outright failures. I always have a protocol to follow. And when families sign up, they also are signing that we've gone through the protocol. So everyone has their phones right next to them. If we get disconnected, I call them and tell them what to do. "-Speech Language Pathologist

- "Sometimes it will disconnect, the video will stop, but the sound will keep going. And usually its very brief."-Speech Language Pathologist 
- "Sometimes I hear an echo... I think that's just part of technology."-Occupational Therapist

- "You have to be comfortable with technology and having to provide therapy in a completely different way than what you're used to. "-Occupational Therapist

- “Technology can be scary for a lot of people."-Occupational Therapist

It is important to note that when asked if there is protocol to follow if technological glitches occur, $100 \%$ of the participants reported that there is a protocol in place and that the clients are aware of them as well. Service providers who do not have experience with telehealth reported similar trends when it comes to technology as a barrier. A majority of the service providers reported that they feel like their families/clients would be reluctant to use telehealth due to the uncertainties of technology and some were not sure if the families/clients would have the proper hardware for telehealth to be a feasible option. One participant reported,

"I think that with technology in general there's a pretty big gap in people who feel comfortable using it versus people who don't."-Occupational Therapist

\section{CHAPTER V. Discussion and Conclusion}

\section{Discussion}

The results from this study reinforce the need for more research to be conducted to determine what factors contribute to the positive and negative perspectives of telehealth in order to help foster practitioner acceptance. The key to the implementation of a successful telehealth program is the provider's acceptance (Serwe, 2018), however, studies have shown that there is a lack of practitioner acceptance when it comes to using telehealth (Cottrell et al., 2018). The aim of this study was to gain a better understanding of what service providers view as the benefits and barriers of telehealth compared to those with telehealth experience and those without. 
Additionally, this study gave some insight on the specific reasons into why service providers may have positive and/or negative perspectives on telehealth. The participants in this study described what they felt were the biggest benefits and barriers when using telehealth as a service delivery model. The results obtained from the interviews and surveys parallels findings found in the literature and demonstrates that the perspectives of telehealth from those with no telehealth experience do not always align with service provider with experience using telehealth.

The most reported benefits from both groups closely aligned with each other. The top three benefits named in this study from service providers who have used telehealth were: improve accessibility of services/care, flexibility in scheduling appointments, and it may promote more engagement and active participation by the client/caregiver. While the top three benefits named in this study from service providers who have not used telehealth were: improve accessibility of services/care, flexibility in scheduling appointments, and reduction of travel time. These findings are consistent with the findings in the literature review of this project.

There were vast differences in the reported barriers from the two groups. The top three barriers named in this study from service providers who have used telehealth were: apprehension by practitioners and clients - mainly service providers who do not have experience with telehealth, limited technology including infrastructure, interoperability, technology difficulties and challenges, and practitioners not ready to adopt a new system of technology due to need for familiarity. The top three barriers named in this study from service providers who have not used telehealth were: lack of physical contact, concerns of decrease quality of care, and apprehension by practitioners and clients. It is interesting to note that two of the top three barriers, according to service providers who have experience with telehealth, explicitly relate to other service providers who do not have or only have limited experience with telehealth. Two of the top three barriers, 
according to service providers who do not have experience with telehealth, relate to efficacy concerns regarding telehealth. This coincides with findings in the literature that being more familiar with telehealth software, having training, or having previous experience with telehealth leads to a higher satisfaction (Serwe, 2018). The findings also support the literature that reported that a lack of acceptance can come from the technical difficulties often found with telehealth, lack of training, lack of physical contact, and resistance to change (Cottrell et at., 2018; Hiratsuka, Delafield, Starks, Ambrose, \& Mala Mau, 2013; Tucker, 2012a).

There are some main take-aways from this study. According to therapists who had not used telehealth, there are too many unknowns for them when it comes to using telehealth and getting started with telehealth:

- "I think it could be beneficial, but there is too much of the unknown. Not sure how useful it would be..."-Occupational therapist

- “Ijust want to learn more!"-Occupational Therapist

- "I don't know how to get involved or even where to start."-Occupational Therapist

- "I just want to know more about telehealth. I want to learn more. I want to be more involved with it."-Physical Therapist

- 'It isn't widely used, there isn't a lot of information available to know how it works and its effectiveness. It isn't taught a lot in MOT programs." - Occupational Therapist According to service providers, many of them were interested in using telehealth, but they did not know how to get started or involved. Additionally, telehealth is just beginning to be taught in schools. If service providers are interested in using it, then they have to take the initiative outside of their career to learn about it. The majority of the service providers expressed interest but lacked the knowledge of knowing how to get started. 
This was also seen when talking with service providers who had used telehealth. Some of them had to take initiative to get started and had to use their own personal money to invest in required equipment. Another mentioned that some telehealth companies prefer to hire service providers who have experience with telehealth or therapists who are more seasoned.

Additionally, many mentioned the lack of regulation and understanding from administrators when it comes to using telehealth. One service provider described how they got into telehealth and their experience with it,

"One of the barriers is people in control of funding the services do not understand what service providers do all day long and what we give to families and that is a problem across the board. There is some confusion between administration and ... you know... I didn't have to pass the test. I didn't have to do certification. I just had one training for early intervention... there is no regulation [with telehealth] right now."-Speech Language Pathologist

Another reported a similar story regarding their experience starting telehealth: "Many of the CEUs weren't related to telehealth," and the therapist went on to say,

"I think it is a giant issue that this [telehealth] is not regulated, it is new, it is different in every state. It's really challenging because different insurances have different policies about it... its really kind of a nightmare for the provider. "-Occupational Therapist

When it comes to legislation and regulation, there are so many layers to it (federal, state, NBCOT, licensing, reimbursement) and it changes so rapidly. These interviews demonstrate that there is a lack of awareness of where to find the regulations and legislations. 
Some service providers have apprehensions when it comes to using telehealth due to its lack of regulation. It also coincides with practitioners who do not have experience with it where they reported fear that something like telehealth has the opportunity of being abused:

- "I think it could be incredibly helpful and appropriate in some situations, but I think there is a risk of abuse and it being used at times when it's clinically inappropriate. I also think there are still many questions in licensure laws and funding streams."-Occupational Therapist

- "Ifeel like it's a great tool but has the possibility of being abused."-Occupational Therapist

- I want to know how to get more involved with it. Because I would hate for something like telehealth get abused... especially with the healthcare system that we currently have. It can be easily swayed and have all opinion and biases. And if it doesn't start off on the right foot, it's going to take a long time to build up why it would be beneficial. If you hear someone who doesn't have a good experience with telehealth, then that person is going to go and tell someone else and eventually no one will be on board with it, especially if they know that there is no one-on-one interaction. "-Physical Therapist

The interviews and surveys demonstrate that fear of abuse, the lack of legislation, and lack of understanding from administrators could be a reason for negative perspectives when it comes to telehealth.

Another theme that emerged is that some service providers who do not have experience with telehealth reported that they feel like there would be an increase in cancellations. This idea of increased cancellation rate also coincides with the idea that clients/families wouldn't necessarily be more involved during telehealth sessions. 
When asked if they felt like telehealth would increase parent participation one service provider reported,

"No, I don't. I think it is an easier thing for them to get out of therapy. I think there could be more cancellations. Like I show up to their house and they can't really not answer the door. They could just be like oh my computer broke or I ran out of battery. So they have more control or power whether or not the kiddo will get the therapy. "-Occupational Therapist

During some of the interviews the researcher asked about the cancellation rate of the clients seen via telehealth. The service providers that were asked reported that the cancellation rate was less than clients seen in person and that telehealth can help mitigate cancellations. One service provider provided statistics from the clinic they work at and reported,

"We actually have a better cancellation rate for telehealth than we did for in the clinic... our overall cancellation rate was about $17 \%$ and, in the clinic, it ranges anything more than 20\%."-Occupational Therapists

Additionally, some of the service providers interviewed who have telehealth reported on client/family involvement when it comes to telehealth sessions. When asked about client/family involvement some of the service providers reported:

- "There is this trend in pediatric therapy where parents just drop off their kid at the clinic and are not involved in session, telehealth allows the parents to be more involved with better carryover at the home. "-Occupational Therapist

- It's just like face to face you have parents that are very into the session and what do you guys need me to work on. And then you have parents that ghost you. You have both of those scenarios in the telehealth world."-Occupational Therapist 
Many of the service providers who reported that there is higher family/client involvement during sessions also reported that there is much more carryover seen in the home.

The last main theme that is important to highlight is that almost all of the service providers who were interviewed mentioned they would only use telehealth if they could use it as a hybrid model. However, the majority of the service providers who use telehealth reported that most of the clients seen using telehealth are part of a hybrid model or that telehealth is used when the client is weaning off service and about to graduate from services. They reported that telehealth is used as an 'additional tool in the clinical toolbox' or an adjunct to in-person services.

\section{Implications for Occupational Therapy}

AOTA recognizes telehealth as a service delivery model to help support engagement of occupations (AOTA, 2014). This study highlights the benefits of using telehealth where occupational therapists can "provide OT services to those who may not have the ability to access it, [so] there's options for them instead of not getting services at all"-Occupational Therapist. This study also provides a better understanding of the provider's experience with telehealth in order to help support the needs of therapists who use telehealth, but also to help support therapists who are interested in telehealth, but do not know how to get started. This study shed some light on possible positive and negative perspectives of using telehealth from service providers who have not used telehealth in order to help determine specific factors on whether or not therapists chose to provide service through telehealth. This comparative study demonstrated that the perspectives of telehealth from those who do not have telehealth experience do not always align with the service providers who have experience using telehealth. Using what was learned from this study can help properly support practitioners in order to improve practitioner 
acceptance of telehealth. This study can also be used to provide education and training from OT programs to continuing education.

\section{Limitations}

Due to the nature of this project, there are were limitations related to it. The limitations include service provider's busy schedules, time constraints of the project, the nature of qualitative research, and sample size. A description of the limitations follows.

The first limitation of this project was working with service provider's busy schedules. Many of the service providers who were interviewed had a time constraint of thirty to forty-five minutes. Some of the interviews were rushed in order to finish the interview and answer all of the questions in time. This meant that some service providers were not asked follow-up questions based on their answers and additional information about details could not be gathered. This was true when scheduling multiple interviews in a week. Many service providers' schedules would change last minute, so interviews had to be postponed or the interview was completed when the service provider had limited time or was driving. Some service providers responded while they were driving, and the audio recording was not clear, or their audio would cut out completely. This made the transcription process much more difficult, and on a few occasions the researcher had to email the service provider to clarify responses. This added an extra challenge during the transcription process. Additionally, at the time of the study, many of the service providers who were supposed to be observed using telehealth no longer had telehealth clients. This meant that there were fewer telehealth observations than originally planned.

Another limitation was time constraints and design of the study due to the nature of this project. Due to changes in the observation timeline, the data collection did not start until October 2019. This added time constraints for the data analysis portion. Due to the limited time to 
analyze the data, only one researcher reviewed and coded the transcripts, so there was not an opportunity for cross-checking the codes. This means that this study has no inter-rater reliability (Armstrong, Gosling, Weinman, \& Martaeu, 1997). Additionally, due to the volume of the data collected, it made the "analysis and interpretation time consuming" (Anderson, 2010, p. 2). This researcher also had limited knowledge and experience when it comes to this type of data analysis used. This study relied on individual skills of the researcher when it came to the data analysis. Accordingly, the data had the opportunity of being “more easily influenced by the researcher's personal biases and idiosyncrasies" (Anderson, 2010, p. 2).

The last main limitation is the sample size. This study used a convenience sample, where participants volunteered to be part of the study. Additionally, this study contained a smaller sample size of forty-six participants. This means the results cannot be generalizable.

One way that this study could have been changed would have been by interviewing the service providers who have no telehealth experience first and then interviewing the service providers who had used telehealth. Just because of the nature of how this project was conducted, the majority of the service providers who used telehealth were the first to be interviewed. When analyzing the results, it became clear that there were some common ideas that some of the service providers who do not have experience with telehealth all shared (i.e. some barriers of telehealth), but those ideas were not mentioned during the interviews with service providers who had experience with telehealth. A better method would have been to gather the most common ideas about barriers and potential issues that the service providers with no telehealth experience felt and then explicitly asking the service providers with experience about those ideas and feelings to compare to the other groups' thoughts about telehealth. 
Lastly, another important note to make is the reasoning behind including all service providers participation in this study instead of limiting the participants to just occupational therapists. The reasoning behind the decision to include all service providers include increase the chances of having a greater sample size, the fact of telehealth is a newer delivery service model within the field of occupational therapy, and having had the opportunity of observing and discussion telehealth with multiple disciplines during the experiential component. The results could have just included occupational therapists, and that would have brought the sample size down to thirty-five (twelve in group one and twenty-three in group two) occupational therapists. Because occupational therapists made up $76 \%$ of the participants, the researcher decided during the data analysis to include all disciplines. Additionally, all disciplines had the opportunity to use telehealth, so it seemed appropriate to be inclusive during the results. Lastly, since telehealth is still considered an emerging practice area within occupational therapy, it was assumed that during the planned design phase, there were not going to be many occupational therapist participants in group one. A longer study would have provided time and the opportunity of the results to just include occupational therapy.

\section{Future Studies}

Based on the results of this study, there is a clear connection that perspectives of those who have not used telehealth do not always align with the experience of those who have used telehealth. Research should look into providing more educational opportunities for students in graduate school while learning about their career. The new Accreditation Council for Occupational Therapy Education (ACOTE) standards were just recently published in 2018 and are effective in 2020 (ACOTE, 2018). The new ACOTE standards mentions telehealth eight times, where the 2011 curriculum, effective in 2013, mentions it six times (ACOTE 2011; 
ACOTE, 2018). Research needs to analyze telehealth content in current entry level curriculum and provide recommendations for curriculum enhancements. Additional educational opportunities may help with apprehension and uncertainties that many service providers who have no telehealth experience may feel when it comes to using it as a way to delivery services. Studies should examine programs that are being taught in school (OTs, OTAs, PTs, PTAs, SLPs, and SLPAs) and see if it increases service providers acceptance when it comes to using telehealth.

Additionally, from the participants that partook in this study, there were some interesting trends. Figure 1.3 (total years using telehealth), demonstrates the increase trend of using telehealth in practice. It highlights just how new telehealth is to the world of rehabilitation, and it emphasizes the need of more rigorous research to support its use. Additionally, when comparing Figure 1.2 with Figure 2.2 (both total years practicing), it appears that the more years a service provider has practiced, the more likely they are to have experience using telehealth. Additional research could be done to either prove or disprove this correlation of length of experience to the likelihood of using telehealth in practice.

Lastly, the results demonstrate the need for more legislation and better regulation of telehealth. Future studies should look into the need of having more consistent legislation and regulations when it comes to using telehealth. Based on the results, some practitioners fear that telehealth has the opportunity of becoming abused, so having stricter laws and regulations and more consistency when it comes to billing, may help promote provider acceptance of telehealth.

\section{Conclusion}

Telehealth is a rapidly growing service delivery model within the field of occupational therapy (Cason, 2014). However, there has been limited research on the perspectives of 
occupational therapists when it comes to the use of telehealth as a service delivery model (Dunleavy, Preissner, \& Finlayson, 2013), and in order to have a successful telehealth program, provider's acceptance is key (Serwe, 2018). The purpose of this study was to gain a better understanding of both the positive and negative perspectives of telehealth by interviewing and surveying service providers who have used and have not used telehealth. The participants were asked about their perspectives about the benefits and barriers of using telehealth as a service delivery model. This study outlines the most frequently recorded benefits and barriers of using telehealth from the perspective of service with and without experience using it as well as the most frequently reported themes from the results. These results were found to be consistent with the benefits and barriers reported in the literature and provide additional insight and a better understanding of the specific reasons for positive and negative perspectives of service providers when it comes to the use of telehealth. With the use of telehealth, occupational therapists can provide their specialty services to those who may not have originally been able to receive services. Some advice to those who wish to get started, but do not know where to start: "Get yourself familiar with the skills that are needed for that service [telehealth]... And then not being scared to try new things because it is not perfect face to face. What makes you think it's going to be perfect online. "-Occupational Therapist 


\section{References}

2011 Accreditation Council for Occupational Therapy Education (ACOTE). (2012). Standards and interpretive guide (effective July 31, 2013). American Journal of Occupational Therapy, 6(6), 1-45.

2018 Accreditation Council for Occupational Therapy Education (ACOTE). (2018). Standards and interpretive guide (effective July 31, 2020). American Journal of Occupational Therapy, 72(2), 1-55.

Anderson, C. (2010) Presenting and evaluating qualitative research. American Journal of Pharmaceutical Education, 74(8), 1-7.

American Occupational Therapy Association. (2011). Definition of occupational therapy practice for the AOTA model practice act. Retrieved from https://www.aota.org/ /media/Corporate/Files/Advocacy/State/Resources/PracticeAct/M odel\%20Definition\%20of\%20OT\%20Practice\%20\%20Adopted\%2041411.pdf

American Occupational Therapy Association. (2014). Occupational therapy practice framework: Domain and process (3rd ed.). American Journal of Occupational Therapy, 68(1), S1S48.

American Occupational Therapy Association (AOTA). (2018). Telehealth in occupational therapy. American Journal of Occupational Therapy, 72(2), 1-27.

Armstrong, D., Gosling, A., Weinman, J., \& Martaeu, T. (1997). The place of inter-rater reliability in qualitative research: An empirical study. Sociology, 31(3), 597-603. Retrieved from http://search.ebscohost.com/login.aspx?direct=true\&db=edsgao\&AN=edsgcl.20378854\& site $=$ eds-live 
Behl, D., Blaiser, K., Cook, G., Barrett, T., Callow-Heusser, C., Moog Brooks, B., Dawson, P., Quigley, S., \& White, K. R. (2017). A multisite study evaluating the benefits of early intervention via telepractice. Infants \& Young Children, 30(2), 147-161.

Baum, C. M., Christiansen, C. H., \& Bass-Haugen, J. (2015). Occupational therapy: performance, participation, and well-being. Thorofare, NJ Slack, Inc. [2015]. Retrieved from http://search.ebscohost.com/login.aspx?direct=true \&db=cat03948a\&AN=usa.8115\&site= eds-live

Braun, V., \& Clarke, V. (2012). Chapter 4: Thematic analysis. In H. Cooper, P. M. Camic, D. L Long, A. T. Panter, D. Rindskopf, \& K. J Sher (Eds), APA handbook of research methods in psychology, Vol 2: Research designs: Quantitative, qualitative, neuropsychological, and biological, (pp. 57-71). Washington, DC: American Psychological Association. https://doi.org/10.1037/13620-004

Brophy, P. D. (2017). Overview on the challenges and benefits of using telehealth tools in a pediatric population. Advances in Chronic Kidney Disease, 24(1), 17-21.

Cason, J. (2012a). An introduction to telehealth as a service delivery model within occupational therapy. OT Practice, 17(7), CE-1-CE-8.

Cason, J. (2012b). Telehealth opportunities in occupational therapy through the Affordable Care Act. American Journal of Occupational Therapy, 66(2), 131-136.

Cason, J. (2014). Telehealth: A rapidly developing service delivery model for occupational therapy. International Journal of Telerehabilitation, 6(1), 29-36.

Clawson, B., Selden, M., Lacks, M., Deaton., A. V., Hall. B., \& Bach R. (2008). Complex 
pediatric feeding disorders: Using teleconferencing technology to improve access to a treatment program. Pediatric Nursing, 34(3), 213-216. Retrieved from http://prxusa.lirn.net/login?url=http://search.ebscohost.com/login.aspx?direct=true $\& \mathrm{db}=\mathrm{ccm} \& \mathrm{AN}$ $=105801781 \&$ site $=$ eds-live

Cole, B., Pickard, K., \& Stredler-Brown, A. (2019). Report on the use of telehealth in early intervention in Colorado: Strengths and challenges with telehealth as a service delivery method. International Journal of Telerehabilitation, (1), 33-40. https://doi.org/10.5195/ijt.2019.6273

Cottrell, M. A., Hill, A. J., O’Leary, S. P., Raymer, M. E., \& Russell, T. G. (2018). Clinicians' perspectives of a novel home-based multidisciplinary telehealth service for patients with chronic spinal pain. International Journal of Telerehabilitation, 10(2), 81-88. https://doi-org.prx-usa.lirn.net/10.5195/ijt.2018.6249

Driessen, J., Castle, N. G., \& Handler, S. M. (2018). Perceived benefits, barriers, and drivers of telemedicine from the perspective of skilled nursing facility administrative staff stakeholders. Journal of Applied Gerontology, 37(1), 110-120. doi:10.1177/0733464816651884

Dunkley, C., Pattie, L., Wilson, L., \& McAllister, L. (2010). A comparison of rural speechlanguage pathologists' and residents' access to and attitudes towards the use of technology for speech-language pathology service delivery. International Journal of SpeechLanguage Pathology, 12(4), 333-343. doi: 10.3109/17549500903456607

Dunleavy, L., Preissner, K. L., \& Finlayson, M. L. (2013). Facilitating a teleconferencedelivered fatigue management program: Perspectives of occupational therapists. Canadian Journal of Occupational Therapy, 80(5), 304-313. Retrieved from 
http://search.ebscohost.com/login.aspx?direct=true\&db=s3h\&AN=94593588\&site=edslive

Estes, J. (2013). The American Occupational Therapy Association advisory opinion for the ethics commission: Telehealth. Retrieved from: https://www.aota.org/ /media/Corporate/Files/Practice/Ethics/Advisory/telehealthadvisory.pdf

Fereday, J. \& Muir-Cochrane, E. (2006). Demonstrating rigor using thematic analysis: A hybrid approach of inductive and deductive coding and theme development. International Journal of Qualitative Methods, 5(1), 1-11.

https://doi.org/10.1177/160940690600500107

Gardner, K., Bundy, A., \& Dew, A. (2016). Perspectives of rural carers on benefits and barriers of receiving occupational therapy via Information and Communication Technologies. Australian Occupational Therapy Journal, 63(2), 117-122. https://doi-org.prxusa.lirn.net/10.1111/1440-1630.12256

Gücin, N. O. \& Berk, O. S. (2015). Technology acceptance in health care: An integrative review of predictive factors and intervention programs. Social and Behavioral Sciences, 195, 1698-1704.

HealthIT.gov. (2017). Telemedicine and telehealth. Retrieved from https://www.healthit.gov/topic/health-it-initiatives/telemedicine-and-telehealth

Hersch, G., Kao, B., Melton, L., \& Pancheri K. (2015). Telehealth usage by occupational therapy practitioners. American Journal of Occupational Therapy, 69(1), 1. doi:10.5014/ajot.2015.69S1-PO1095. 
Hiratsuka, V., Delafield, R., Starks, H., Ambrose, A. J., \& Mala Mau, M. (2013). Patient and provider perspectives on using telemedicine for chronic disease management among native Hawaiian and Alaska native people. International Journal of Circumpolar Health, 72, 1-7. doi:10.3402/ijch.v72i0.21401

Irfanahemad, A. S., Nandakumar, B. S., \& Radhiki, K. (2018). Use of unified theory of acceptance and use of technology model for telemedicine services: An exploratory study. International Journal of Community Medicine and Public Health, 5(9), 4112-4118.

Jacobs, K., Cason, J., \& McCullough, A. (2015). The process for the formulation of the international telehealth position statement for occupational therapy. International Journal of Telerehabilitation, 7(1), 21-32. https://doi-org.prx-usa.lirn.net/10.5195/ijt.2015.6163

Kandola, D. K., Banner,D., Araki, Y., Bates, J., Hadi, H., Lear, S. A. (2018). The Participant Recruitment Outcomes (PRO) study: Exploring contemporary perspectives of telehealth trial non-participation through insights from patients, clinicians, study investigators, and study staff. Contemporary Clinical Trials Communications, 11, 75-82. https://doi.org/10.1016/j.conctc.2018.05.005

Kessler, D., \& Graham, F. (2015). The use of coaching in occupational therapy: An integrative review. Australian Occupational Therapy Journal, 62(3), 160-176. https://doi-org.prx-usa.lirn.net/10.1111/1440-1630.12175

Lincoln M., Hines, M., Fairweather, C., Ramsden, R., \& Martinovich., J. (2015). Multiple stakeholder perspectives on teletherapy delivery of speech pathology services in rural schools: A preliminary, qualitative investigation. International Journal of Telerehabilitation, 6(2), 65-74. https://doi-org.prx-usa.lirn.net/10.5195/ijt.2014.6155 
Little, L. M., Pope, E., Wallisch, A., \& Dunn, W. (2018). Occupation-based coaching by means of telehealth for families of young children with Autism Spectrum Disorder. American Journal of Occupational Therapy, 72(2), 1-7. https://doi-org.prx-usa.lirn.net/10.5014/ajot.2018.024786

Mammen, J. R., Elson, M. J., Java, J. J., Beck, C. A., Beran, D. B., Biglan, K. M., Boyd, C. M., Schmidt, P. N., Simone, R., Willis, A. W, Dorsey, E. R. (2018). Patient and physician perceptions of virtual visits for Parkinson's disease: A qualitative study. Telemedicine \& E-Health, 24(4), 255-267. doi:10.1089/tmj.2017.0119

Meadan, H., \& Daczewitz, M. E. (2015). Internet-based intervention training for parents of young children with disabilities: A promising service-delivery model. Early Child Development and Care, 185(1), 155-169. Retrieved from http://search.ebscohost.com/login.aspx?direct=true\&db=eric\&AN=EJ1047398\&site=edslive

Nobakht, Z., Rassafiani, M., Hosseini, S. A., \& Ahmadi, M. (2017). Telehealth in occupational therapy: A scoping review. International Journal of Therapy \& Rehabilitation, 24(12), 534-538. https://doi.org/10.12968/ijtr.2017.24.12.534

Odeh, B., Kayyali, R., Gebara, S. N., \& Philip, N. (2014). Implementing a telehealth service: Nurses' perceptions and experiences. British Journal of Nursing, 23(21), 1133-1137. https://doi.org/10.12968/bjon.2014.23.21.1133

Research Guide. (2019). Quantitative vs. qualitative data. Retrieved from https://libguides.macalester.edu/c.php?g=527786\&p=3608639

Richards, H., King, G., Reid, M., Selvaraj, S., McNicol, I., Brebner, E., \& Godden, D. (2005). Remote working: Survey of attitudes to eHealth of doctors and nurses in rural general 
practices in the United Kingdom. Family Practice, 22(1) 2-7. http://prx-

usa.lirn.net/login?url=http://search.ebscohost.com/login.aspx?direct=true $\& \mathrm{db}=$ edsovi\&A $\mathrm{N}=$ edsovi.00003856.200502000.00002\&site=eds-live

Serwe, K. M. (2018). The provider's experience of delivering an education-based wellness program via telehealth. International Journal of Telerehabilitation, 10(2), 73-80. https://doi-org.prx-usa.lirn.net/10.5195/ijt.2018.6268

Smith, D., \& Hudson, S. (2012). Using the Person-Environment-Occupational Performance conceptual model as an analyzing framework for health literacy. Journal of Communication in Healthcare, 5(1), 3. https://doi.org/10.1179/1753807611Y.0000000021

Tucker, J. K. (2012a). Perspectives of speech language pathologists on the use of telepractice in schools: The qualitative view. International Journal of Telerehabilitation, 4(2), 47-60.

Tucker, J. K. (2012b). Perspectives of speech language pathologists on the use of telepractice in schools: Qualitative survey results. International Journal of Telerehabilitation, 4(2), 4760.

Venkatesh, V., Morris, M., Davis, G., \& Davis, F. (2003). User acceptance of information technology: Toward a unified view. MIS Quarterly, 27(3), 425-478. doi: $10.2307 / 30036540$

Wisdom, J. \& Creswell, J. W. (2013). Mixed-methods: Integrating quantitative and qualitative data collection and analysis while studying patient-centered medical home model. Agency for Healthcare Research and Quality, 13-0028-EF, 1-5.

Retrieved from https://pcmh.ahrq.gov/page/mixed-methods-integrating-quantitative-andqualitative-data-collection-and-analysis-while 
World Federation of Occupational Therapists. (2014). World Federation of occupational therapists' position statement on telehealth. International Journal of Telerehabilitation, 6(1), 37-40. doi:10.5195/ijt.2014.6153 


\section{APPENDIX A}

Interview Questions Service Providers Who Have Used Telehealth 
Pre-recording: Hello [Insert Name], thank you for participating in my interview about service providers perspectives about telehealth. My name is Taylor Corey and I am an occupational therapy doctoral student researching service providers perspectives about telehealth. This study was approved by the IRB board at the University of St. Augustine for Health Sciences. For this study, the interview will be audio recorded with your consent, but this is not required. The recording will not include your name or any personal information, however, you will be consenting to the use of quotes during the analysis process. Are you okay with me recording this session? If you are not, then we will still continue on with the interview for my project purposes, but the information you provide me will not be used in the research study. Are you willing to consent to the recording process?

Recording: Before we begin I would like to remind you that you were emailed the consent form prior to this interview. By saying 'yes' you are willing to participate in this research study and are consenting to audio record this interview. Do you have any questions? Do you consent to participate in this study? [Yes]. Let's begin- today is [Insert date and time].

1. What is your profession?

2. How long have you been working in [blank] profession?

3. What state(s) do you practice in?

4. What state(s) do you hold your license?

5. What populations do you primarily work in?

6. If works in EI:

a. How long have you been working in Early Intervention (EI)?

b. Telehealth is used for which percentage of your EI program?

7. How long have you been using telehealth to provide services?

8. What percentage of your clients do you use telehealth with?

a. Do you purposefully choose telehealth for some clients versus others?

9. Do you enjoy using telehealth as a service delivery model?

10. Can you describe why you would use telehealth or not?

11. How would you compare the progress your patients make that use telehealth and those that do not?

12. Do you find that families and caregivers are more involved or less involved in therapy if you use telehealth or not?

13. Do you ever experience technological failures or glitches? 
a. How often?

b. What is your protocol when this happens?

14. To you, what are the benefits of telehealth services?

15. What do you think are the barriers of telehealth services?

16. Literature has shown that some people are apprehensive about using telehealth. Do you agree or disagree?

a. Why do you think that is?

17. Would you recommend telehealth to your patients?

a. Are there clients you would not recommend telehealth to?

18. What do you like best about telehealth?

19. What do you like least about telehealth?

20. Is there anything you would like to me to know about your perspectives about telehealth? 
APPENDIX B

Interview Questions Service Providers Who Have Never Used Telehealth 
Pre-recording: Hello [Insert Name], thank you for participating in my interview about service providers perspectives about telehealth. My name is Taylor Corey and I am an occupational therapy doctoral student researching service providers perspectives about telehealth. This study was approved by the IRB board at the University of St. Augustine for Health Sciences. For this study, the interview will be audio recorded, transcribed, analyzed, and coded. The recording will not include your name or any personal information, however, you will be consenting to the use of quotes during the analysis process. Are you okay with me recording this session? If you are not, then we will still continue on with the interview for my project purposes, but the information you provide me will not be used in the research study. Are you willing to consent to the recording process?

Recording: Before we begin I would like to remind you that you were emailed the consent form prior to this interview. By saying 'yes' you are willing to participate in this research study and are consenting to audio record this interview. Do you have any questions? Do you consent to participate in this study? [Yes]. Let's begin- today is [Insert date and time].

1. What is your profession?

2. How long have you been working in [blank] profession?

3. What state(s) do you practice in?

4. What state do you hold your license?

5. What populations do you primarily work in?

a. If EI: how long have you worked in EI?

b. Do your colleagues use telehealth?

6. Are you interested in using telehealth?
a. Why or why not?
b. If interested: why haven't you used telehealth?
c. Not interested: Why?

7. When do you think telehealth would be beneficial?

a. OR: do you see any benefits with using telehealth?

8. What do you think are the barriers of telehealth services?

9. Literature has shown that some people are apprehensive about using telehealth. Do you agree or disagree?
a. Why do you think that is?

10. Would you recommend telehealth to your patients?

11. Is there anything you would like to me to know about your perspectives about telehealth? 
APPENDIX C

Survey for Service Providers Who Have Used Telehealth 
Perspectives of Service Providers on the Benefits and Barriers on Providing Services via Telehealth

Information included at the beginning of the survey: I would like to invite you to take part of a research that examines the perspectives of telehealth services. If you are willing to participate in this study, you will be asked questions related to your opinions, experiences, and perspectives of telehealth. You do not have to have any telehealth experience to participate in this study. The study should take about 10 minutes to complete. By taking part of this survey, you are consenting to participate. If you have any questions or concerns please contact Taylor Corey, OTDS at t.corey@usa.edu.

THIS PROJECT HAS BEEN REVIEWED AND APPROVED BY THE UNIVERSITY OF ST. AUGUSTINE FOR HEALTH SCIENCES INSTITUTIONAL REVIEW BOARD FOR THE PROTECTION OF HUMAN SUBJECTS.

IF YOU HAVE QUESTIONS OR CONCERNS, PLEASE CONTACT THE INSTITUTIONAL IRB CHAIR, DR. ELIZABETH ARDOLINO, EMAIL: EARDOLINO@USA.EDU, PHONE: 737-202-3343.

1. By clicking yes, you are consenting to participate in this study
a. Yes

2. Please indicate your discipline

a. Occupational Therapist

b. Occupational Therapy Assistant

c. Speech and Language Pathologist

d. Speech and Language Pathologist Assistant

e. Physical Therapist

f. Physical Therapy Assistant

g. Other (please specify)

3. How long have you been working as the service provider you put in question 2 ?
a. 0-5 years
b. 6-10 years
c. 11-15 years
d. $16+$ years

4. What state do you hold your license?

a. Comment here:

5. What populations do you primarily work in?
a. Pediatrics
b. Adults
c. Geriatrics
d. Other (please specify): 
6. Do you work in Early Intervention (EI) ? (If 'no,' please put no and skip question 7 and 8)
a. Yes
b. No

7. How long have you been working in Early Intervention (EI)? If you said no to question 6, please skip.
a. $0-5$ years
b. 6-10 years
c. 11-15 years
d. $16+$ years

8. Telehealth is used for which percentage of your EI program. If you said no to question 6, please skip.
a. $0-10 \%$
b. $11-25 \%$
c. $26-50 \%$
d. More than $50 \%$

9. How long have you been using telehealth to provide services?
a. $0-5$ years
b. 6-10 years
c. 11-15 years
d. $16+$ years

10. Telehealth is used for which percentage of your clients (don't' fill out if did EI question 8)
a. $0-10 \%$
b. $11-25 \%$
c. $26-50 \%$
d. More than $50 \%$

11. I have used telehealth before and.... (check all that apply)
a. I didn't like using it
b. I liked using it
c. I didn't think my patients benefited from it
d. Some of my patients benefited from it
e. Comment:

12. I use telehealth for (check all that apply)
a. Provider illness
b. Child/family illness
c. Inclement weather
d. 'Off' hours sessions
e. Reduce travel
f. Patient/Parent request 
g. Providing services in a different state

h. Other (please specify)

13. Compared to patients I see in person; I find that the patients I see via teleh ealth sessions make:
a. More progress
b. About the same progress
c. Less progress
d. Other (comment):

14. Technology I use works:
a. At least $90 \%$ of the time
b. About $75-89 \%$ of the time
c. About half the time
d. Less than half the time

15. Please specify the reasons on when it doesn't work:
a. Comment:

16. From a subjective standpoint, what do you feel are the benefits of telehealth services (check all that apply):
a. Improved access of care
b. Reduced travel time
c. Prevention of delays to see a specialist
d. A cost-effective tool for providing services
e. More personalized care
f. Flexibility in scheduling appointments
g. May promote more engagement and active participation by the patient/caregiver
h. I don't think there are benefits
i. Other (please specify):

17. What do you think are the barriers of telehealth services (check all that apply)?
a. Financial difficulties including lack of reimbursement, sustained funding, and/or initial investment required
b. Limited technology including infrastructure, interoperability, technology difficulties and challenges
c. Apprehension by practitioners and clients
d. Practitioners not ready to adopt a new system of technology due to need for familiarity
e. Privacy and security concerns
f. State licensure issues
g. The need of more rigorous research to help support the use of telehealth
h. Other (please specify):

18. Positive perspectives on using telehealth come from (check all that apply):

a. Having previous experience with telehealth 
b. Being a younger age

c. Having training and familiarity with technology

d. The idea of reduced travel time for therapists

e. Economic savings (cost effective medium)

f. Patients are able to access care in their home

g. Improved timeliness of care

h. Other (please specify):

19. Why do you think some service providers are apprehensive about using telehealth (please check all that apply)?

a. Concerns of increased workload

b. Concerns of decrease quality of care

c. Concerns regarding confidentiality and privacy

d. Concerns of establishing therapeutic relationships

e. Concerns involving technology issues and failures including communication lapse or delay, poor connection (audio and/or visual), suboptimal image clarity, lack of reliable technology

f. Lack of physical contact

g. Lack of practitioner acceptance due to resistance to change

h. Lack of practitioner acceptance due to uncertainty about telehealth

i. Lack of research

j. Financial challenges- lack of reimbursement

k. Financial challenges- lack of sustained funding

1. Other (please specify):

20. Would you recommend telehealth to your patients?
a. Yes
b. No
c. Maybe
d. Please explain

21. What do you like best about telehealth?

a. Please specify:

22. What do you like least about telehealth?

a. Please Specify:

23. Is there anything you would like to me to know about your perspectives about telehealth? a. Comment: 
APPENDIX D

Survey for Service Providers Who Have Never Used Telehealth 
Perspectives of Service Providers on the Benefits and Barriers on Providing Services via Telehealth

I would like to invite you to take part of a research that examines the perspectives of telehealth services. If you are willing to participate in this study, you will be asked questions related to your opinions, experiences, and perspectives of telehealth. You do not have to have any telehealth experience to participate in this study. The study should take about 10 minutes to complete. Please answer each question as honestly and truthfully as you can. By taking part of this survey, you are consenting to participate. If you have any questions or concerns please contact Taylor Corey, OTDS at t.corey@usa.edu.

THIS PROJECT HAS BEEN REVIEWED AND APPROVED BY THE UNIVERSITY OF ST. AUGUSTINE FOR HEALTH SCIENCES INSTITUTIONAL REVIEW BOARD FOR THE PROTECTION OF HUMAN SUBJECTS.

IF YOU HAVE QUESTIONS OR CONCERNS, PLEASE CONTACT THE INSTITUTIONAL IRB CHAIR, DR. ELIZABETH ARDOLINO, EMAIL: EARDOLINO@USA.EDU, PHONE: 737-202-3343.

1. By clicking yes, you are consenting to participate in this study
a. Yes

2. Please indicate your discipline

a. Occupational Therapist

b. Occupational Therapy Assistant

c. Speech and Language Pathologist

d. Speech and Language Pathologist Assistant

e. Physical Therapist

f. Physical Therapy Assistant

g. Other (please specify)

3. How long have you been working as the service provider you put in question 2:
a. $0-5$ years
b. 6-10 years
c. 11-15 years
d. $16+$ years

4. What state do you hold your license?

a. Comment here:

5. What populations do you primarily work in?
a. Pediatrics
b. Adults
c. Geriatrics
d. Other (please specify): 
6. Do you work in Early Intervention (EI) ? (If no, please put no and skip question 7)
a. Yes
b. No
c. Un

7. How long have you been working in Early Intervention (EI)? If you said no to question 6, please skip.
a. $0-5$ years
b. 6-10 years
c. 11-15 years
d. $16+$ years

8. Are you interested in using telehealth? (If 'yes', please skip question 10, if 'no,' please skip question 9)
a. Yes
b. No
c. Undecided

9. If you answered 'yes' to question 8, why have you not used telehealth? (Skip if answered 'no' to question 8).

a. Comment here:

10. If you answered 'no' to question 8, why are you not interested in telehealth? (Skip if answered 'yes' to question 8).

a. Comment here:

11. If you answered 'undecided' to question 8, why are you unsure about telehealth? (Skip if answered 'yes' or 'no' to question 8).

a. Comment here:

12. What do you think are the benefits of using telehealth services (check all that apply)?

a. Improved access of care

b. Reduced travel time

c. Prevention of delays to see a specialist

d. A cost-effective tool for provide services

e. More personalized care

f. Flexibility in scheduling appointments

g. May promote more engagement and active participation

h. I don't think there are benefits

i. Other (please specify):

13. What do you think are the barriers of telehealth services (check all that apply)?

a. Financial difficulties including lack of reimbursement, sustained funding, and/or initial investment required

b. Limited technology including infrastructure, interoperability, technology difficulties and challenges 
c. Apprehension by practitioners and clients

d. Practitioners not ready to adopt a new system of technology due to need for familiarity

e. Privacy and security concerns

f. State licensure issues

g. The need of more rigorous research to help support the use of telehealth

h. Other (please specify):

14. Positive perspectives on using telehealth (i.e: positive viewpoint on telehealth) come from (check all that apply):
a. Having previous experience with telehealth (as a patient)
b. Being a younger age
c. Having training and familiarity with technology
d. The idea of reduced travel time for therapists
e. Economic savings (cost effective medium)
f. Patients are able to access care in their home
g. Improved timeliness of care
h. Other (please specify):

15. Why do you think some service providers are apprehensive about using telehealth (please check all that apply)?
a. Concerns of increased workload
b. Concerns of decrease quality of care
c. Concerns regarding confidentiality and privacy
d. Concerns of establishing therapeutic relationships
e. Concerns involving technology issues and failures including communication lapse or delay, poor connection (audio and/or visual), suboptimal image clarity, lack of reliable technology
f. Lack of physical contact
g. Lack of practitioner acceptance due to resistance to change
h. Lack of practitioner acceptance due to uncertainty about telehealth
i. Lack of research
j. Financial challenges- lack of reimbursement
k. Financial challenges- lack of sustained funding
1. Other (please specify):

16. Would you recommend telehealth to your patients?
a. Yes
b. No
c. Please explain

17. Is there anything you would like to me to know about your perspectives (i.e. viewpoint) about using telehealth?
a. Comment: 
APPENDIX E

\section{Email and Survey Post Introduction}


Hello,

My name is Taylor Corey and I am an occupational therapy doctorate student at the University of St. Augustine at the San Marcos, CA campus. I am currently working on my OTD capstone project in the area of Telehealth. More specifically, I am examining the provider's perspective about the strengths and barriers of telehealth related to the field of occupational therapy. During my research, I noticed that there is a gap in the occupational therapy research on the practitioner's perspective on telehealth.

For my project, I plan to talk with as many service providers as possible, in and outside the field of OT, who use telehealth and discuss their perspectives on telehealth services. In addition, I would also like to talk to service providers who have never used telehealth, who have used telehealth and did not like it, and those that are interested in telehealth, but have not had experience with it.

If you are a service provider and would be interested in being interviewed, please contact me at t.corey@usa.edu. The interviews will take about 30-45 minutes to complete, all questions are open-ended. Interviews will have the option of being recorded, but it is not required. All answers are confidential and no personal information will be used.

Additionally, if you would like to participate in a survey or do not have time for an interview and would still like to participate, below is a link to a survey. The survey should only take about 10 minutes to complete. By completing the survey, you are consenting to participate in this study. The top line is for service providers who have used telehealth and the bottom link is for service providers who have never used telehealth.

I have used telehealth: https://forms.gle/Tpd53N6WpfeXhnrh6

I have never used telehealth: https://forms.gle/z6KFQS6XVGCr6vfL6

If you know any service providers who would be interested in taking the survey or being interviewed, I would greatly appreciate if you could forward them my information!

Thank you so much. If you have any questions, please contact me at: t.corey@usa.edu

Best,

Taylor Corey, OTDS

University of St. Augustine, San Marcos 


\section{APPENDIX F}

PowerPoint Deliverable to San Diego Regional Center 
A Telehealth Introduction for Service Coordinators

Taylor Corey, OTD/S

Rebecca Johnston, OTD/S
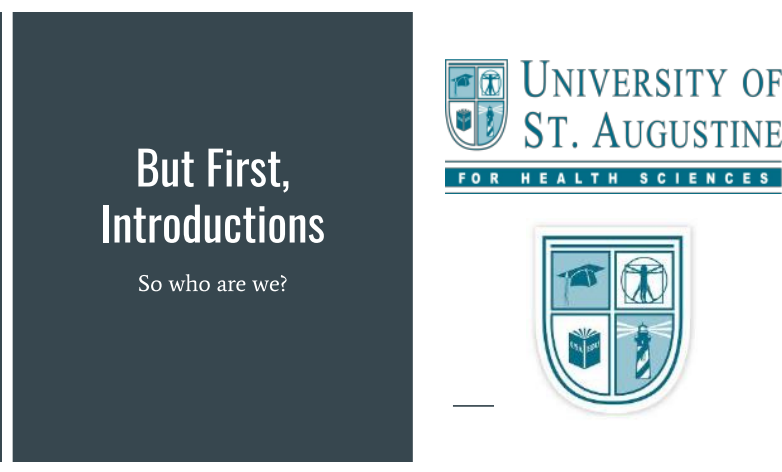

"Telemedicine will become the core methodology of healtheare delivery in the future. That is where we are going to get the effifieiencies we need to provide affordable care"

Vulun Wang, President of American Telemedicine Association

"We do not have enough physicians and physician extenders to treat all the patients who need access to care. Telehealth should be a viable option for access and will be important as we move forward

Marta Green, Chief Deputy Director of Department of Managed Care at Califiornia Telehealth Network

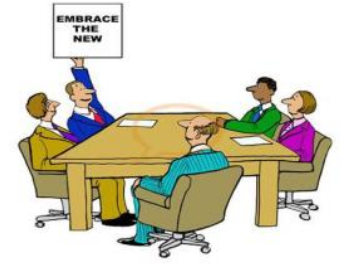

Telehealth Benefits

What is Telehealth?

A service model that utilizes communication technologies to not in the same location (WFOT, 2014)

Can be used in various practice settings (Cason, Hartmann.

- Can be used for evaluations, consultations, monitoring.

"Telehealth is not a distinct and separate intervention" (Cason, 2014, p 30)
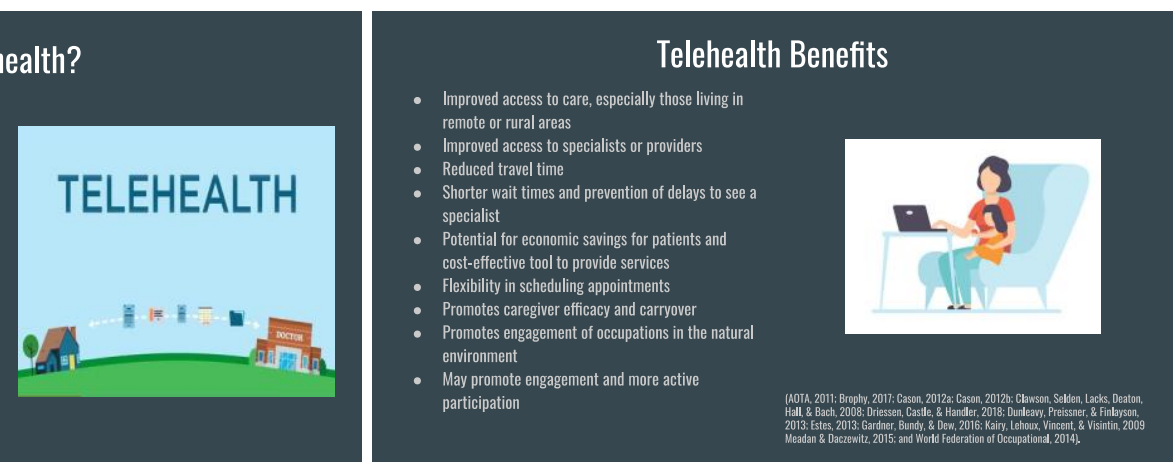

Telehealth Barriers

- Technology challenges

martphon

- Lack of access to computer

Need for computer literacy

Apprehension by practitioners and clients Privacy and security concerns

Lack of physical contact

Less personal

- Lack of hands-on treatment for clients that may require this type of approach (i.e: NDT, PAMs, splinting)

Concerns relating to the client-practitioner therapeutic relationship

- State licensure issues

Need for more rigorous research to help support the use of telehealth
Why Telehealth in Early Intervention?

- Telehealth is recognized for OT, PT, and ST as an appropriate and effective model to provide early intervention services

Increases participation of child and family

- Care can take place in the natural environment of the child, and during normal routines of the family (i.e. feeding during regular mealtime)

- Utilizes the coaching model, which helps to empower families with the care of their child 

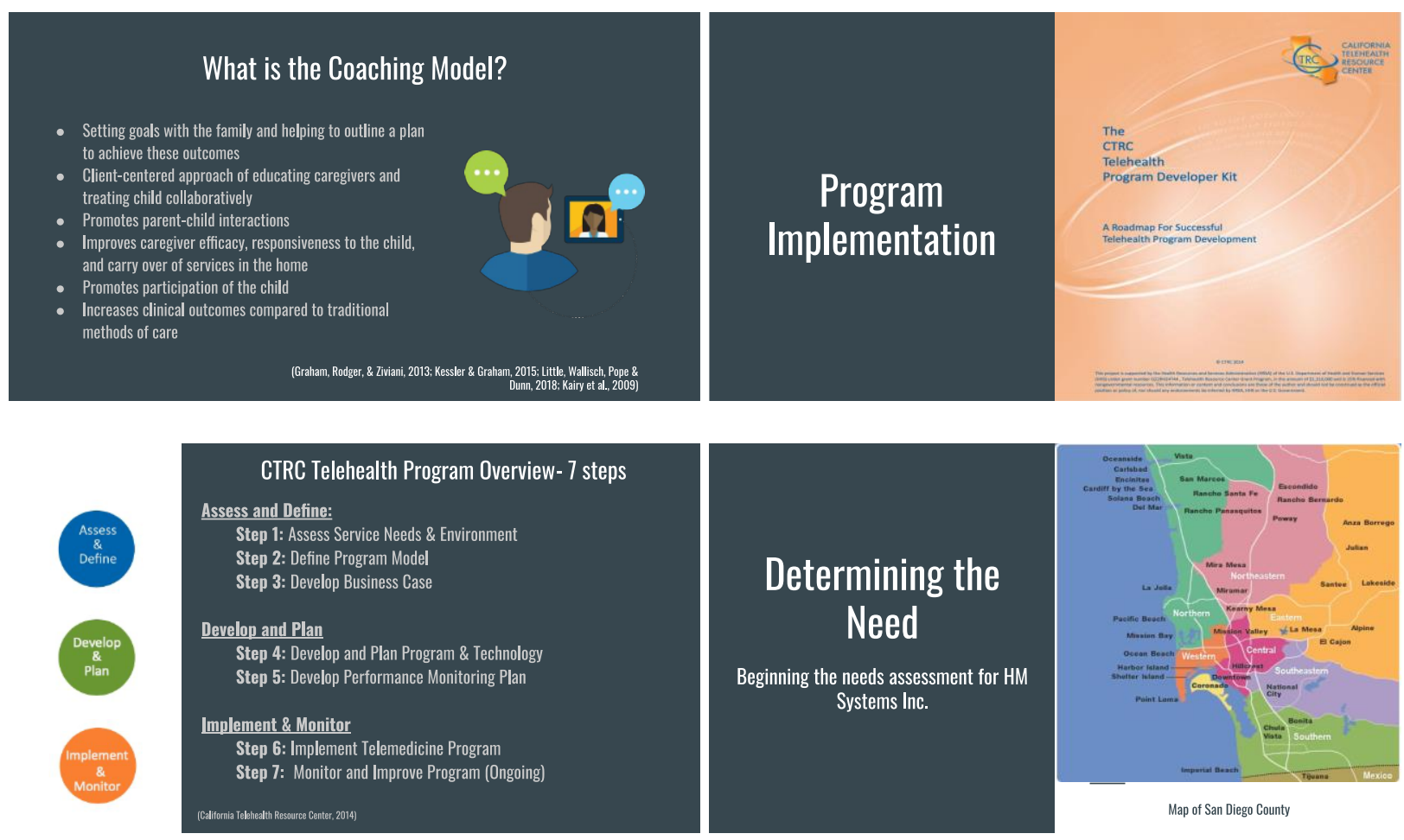

"Especially [for] the more rural families where I've had

trouble saying no to in the past. I've gone out of my way for those kiddos, when they [Regional Center] can't find a therapist to go out and see them... I know for me, I've had to turn down families, that maybe telehealth would have allowed me to work... So, if /'m able to provide my expertise and my training to them and this is the best option to do it versus having nothing, then I'm open to definitely exploring

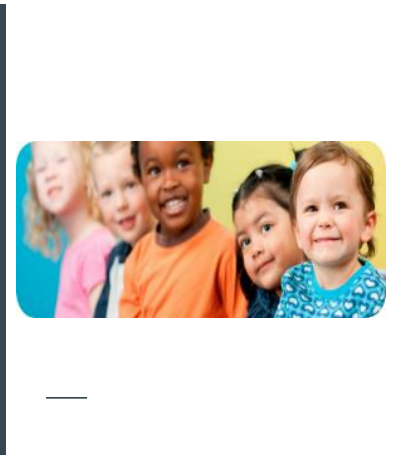

Case Examples telehealth, especially in those instances"

-Occupational Therapist.

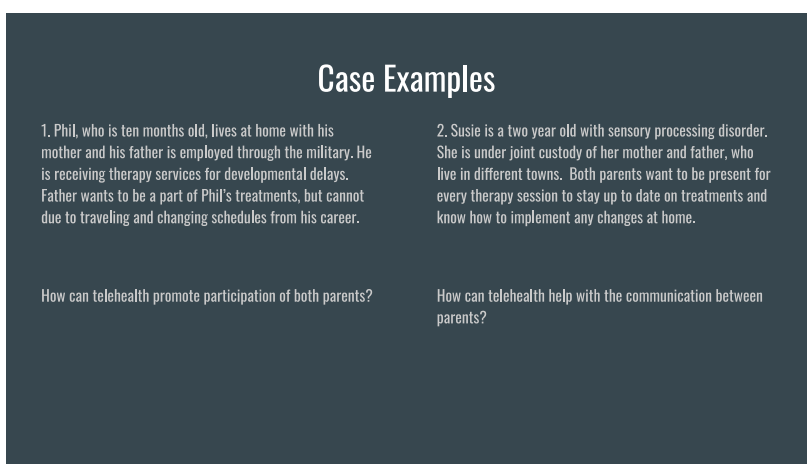

Case Examples

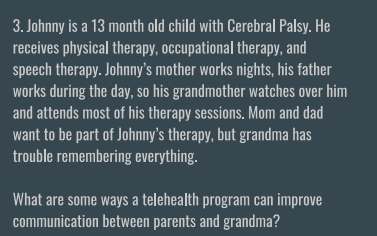

4. Mary is a 6 month old child who is medically fragile and whose family lives in the mountains in east San Diego County. There are no service providers that are able to provide services in the home and the closest therapy appointment that the parents can get is 4 hours away.

\section{Our Projects...}


Most Reported Benefits- Therapist's Perspectives of Telehealth

Providers Who Have Used Telehealth:

Improve accessibility of services/care $(88 \%)$

Flexibility in schechlims appohithents $69 \%$

May promote more engagement and active participation by

the client/caregiver (63\%)

Reduce travel time $(63 \%$

Prevention of delays to see a specialist $(38 \%)$

A cost-effeetive tool for providing services $(38 \%)$

Helps with transitions within the home environment

8. Mitigate cancellations $(19 \%$
Providers Who Have Not Used Telehealth:

Improve aceessibility of services/care $(87 \%$ Hexiblity in scheduling appointments $(77 \%$ Reduced travel time $70 \%$

Prevention of delays to see a specialist ( $60 \%)$

A cost-eifiective tool for providing services $(37 \%)$

by the client//caregiver $33 \%$;

Tool for referrals, consultations, and screens (16\%)

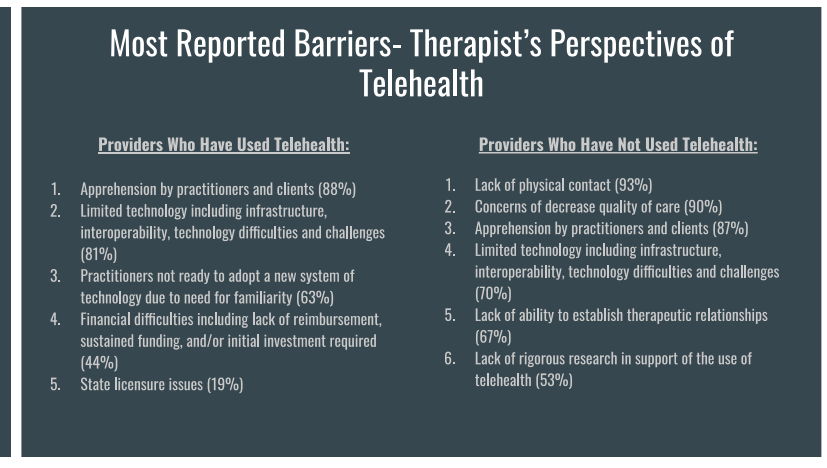

Most Reported Benefits- Caregiver's Perspectives of Telehealth

Caregivers Who Have Used Telehealth:

Improved flexibility in appointment scheduling (100\%)

Decreased travel time to appointments (50\%)

Improved access to healthcare $(50 \%$

Easier to receive services in home and during normal

housentiold schedules $(50 \%)$

Method of collaboration with the therapist ( $50 \%$

6. "I love everything about itt" (50\%)
Garegivers Who Have Not Used Telehealth:

Decreased travel time to appointments $(77.8 \%)$

Improved flexibility in appointment scheduling (66.7\% Easier to receive services in home and during norma houschold schedules $(66.7 \%)$

Improved access to healthcare $(33.3 \%)$

Improved access to healthcare (33.3\%)
Method of collaboration with therapist (22.2\%)

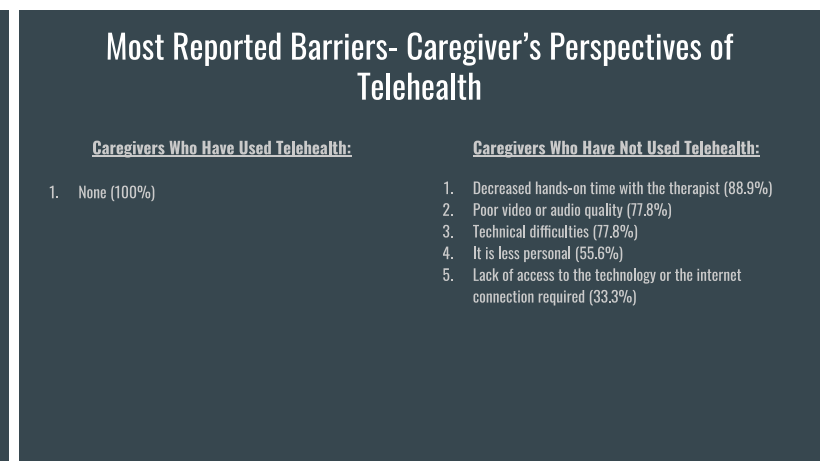

Provider's Perceptions of Telehealth

- "I think it is an easier thing for them to get out of I show up to their house and they can't really not answer the door. They could just be like oh my computer broke or I ran out of battery. So they have more control or power whether or not the kiddo wili get

"Once therapists have a routine of how they do things and it's a system that works well. You are reluctant to change." - Occupational Therapis

- "lam apprehensive as I find it easier to have in person conversations so I can use language and hands on techniques to ensure full comprehension. However, also feel that maximizing services and availability of services to people is beneficial." -Physical Therapis
Provider's Experiences with Telehealth:

"We actually have a better cancellation rate for telehealth than we did for in the clinic our overal cancellation rate was about $17 \%$ and in the clinic ranges anything more than 20\%"-0ccupational

- "There is this trend in pediatric therapy where parents just drop off their kid at the clinic and are not involved in session, telehealth allows the parents to be more involved with better carryover at the home."-0ccupational Therapist

- "It's because it's an emerging area for professionals, so not everyone understands what online sessions entail. And not everyone understands that therapy doesn't mean having your hands on a patient throughout the whole session." - Occupational Therapist

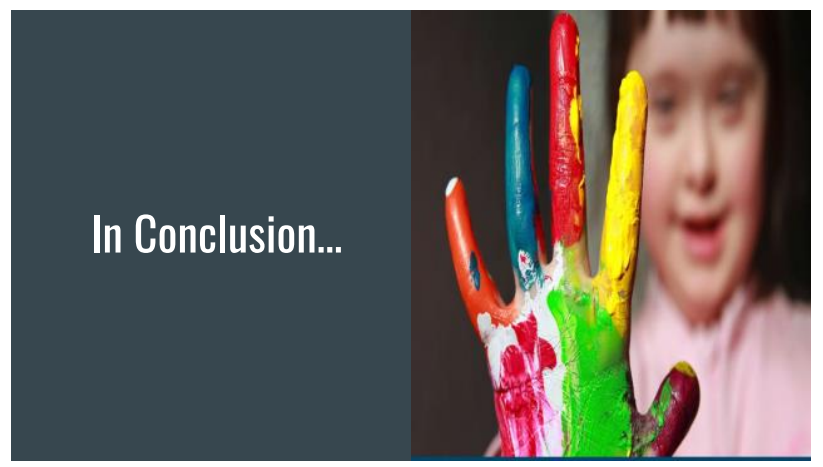

\section{Families' Perceptions of Telehealth}

- "I'm not sure it would be more beneficial than in-person visits, besides travel time and possibly cost"

- "'d prefer an in person and hands on experience."

- "I think it is a great concept to have access to even if it is not my personal first choice."

- "It might work for other families, but not for me." Using the Coaching Model: $\mathrm{g}$-interaction-style/

HIPAA and Telehealth: https://www.hipajournal.com/hipaa-guidelines-on-telemedicin

Developing a Telehealth Program: Ittps://www.teleheathiresourcecenter.org/wp-content/aplods 2014 df https://www.aota.org/Practice/Manage/telehealth.aspx

APTA Telehealth Resources:

ASHA Telehealth Resources:

https://www.asha.org/Practice-Portal/Professional-lssues/Tele families' Experiences with Telehealth:

- "I have been extremely satisfied. I love my OT provider, and l've received excellent services from a highly
qualified therapist."

- "I really like it because I learn hands on. I f feel that the "ance

"Ive received services that we wouldn't have had access to in my community. Also my son is often shy when we leave the house, so if $\mathrm{l}$ had to go to a facility for therapy, it might take most of the session for him to

"I would recommend it to parents who explicitly agree that their child needs intervention. I don't think it would work as well for parents who are reluctant participants."

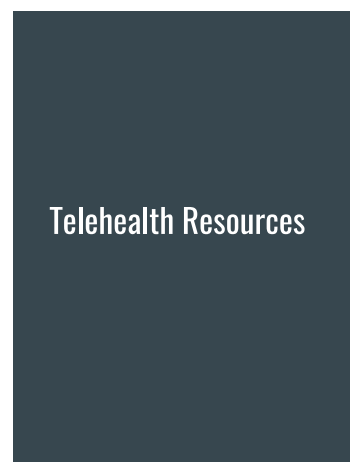



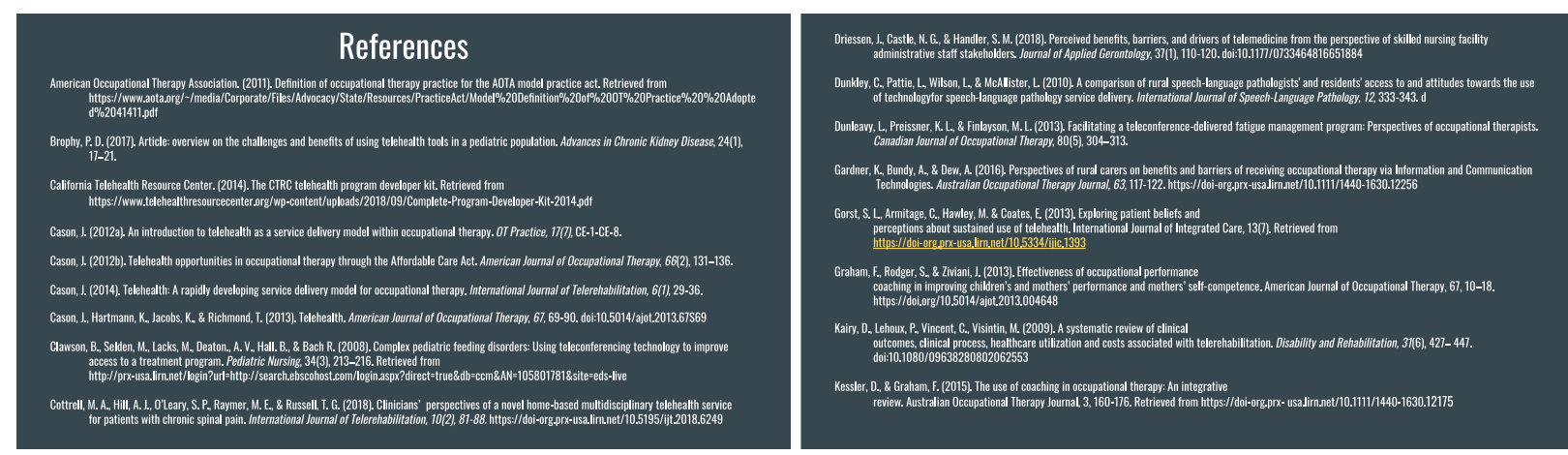

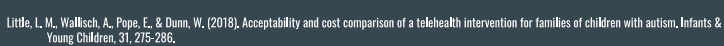

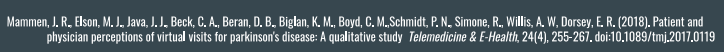

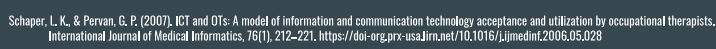

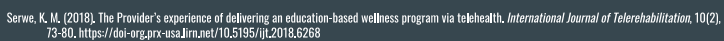

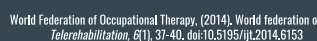

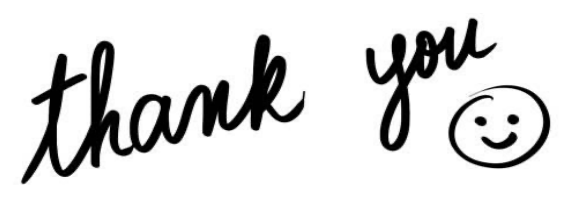

\section{Questions?}


APPENDIX G

PowerPoint Deliverable to HM Systems Staff 


\section{A Telehealth Introduction for} Service Providers

Taylor Corey, OTD/s

Rebecca Johnston, OTD/s
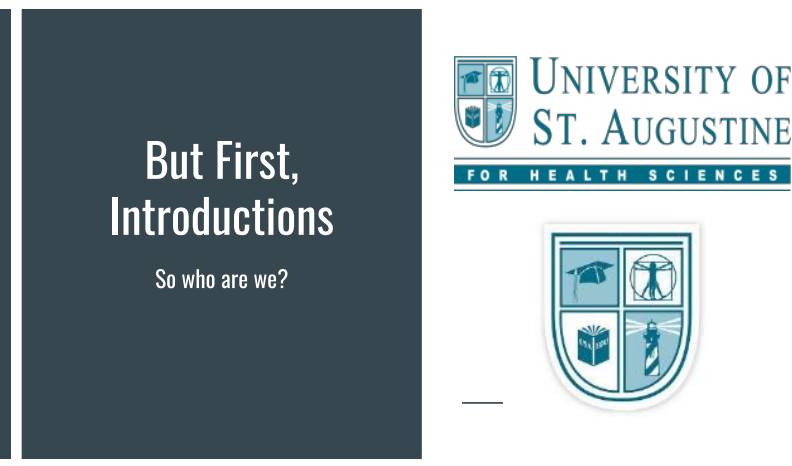

Learning Objectives

$\star$ Understand the use of telehealth as a service delivery model

$\star$ Illustrate and provide evidence based research on the benefits of telehealth service delivery model in family centered Early Intervention

$\star$ Introduce Coaching Model and its use with telehealth

$\star$ Overview of therapist perspectives and caregivers perspectives of telehealth based on our capstone projects

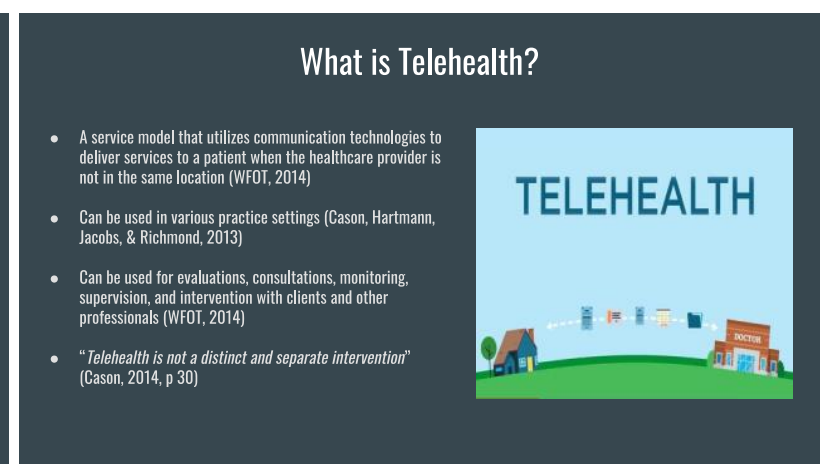

What do you think are the benefits of telehealth?

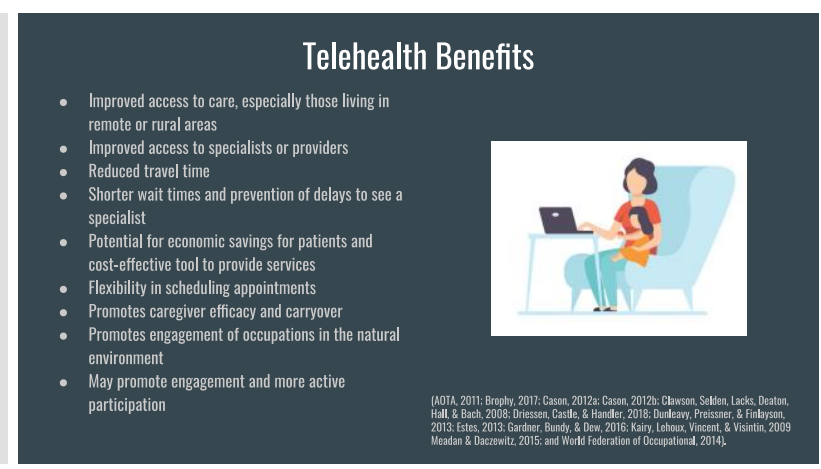

Telehealth Barriers

- Technology challenges

- Lack of access to computer or smartphone

- Need for computer literacy

- Apprehension by practitioners and clients Privacy and security concerns Lack of physical contact

What do you think could be barriers of telehealth?

Lack of hands-on treatment for clients that may require this type of approach (iie: NDT PAMs, splinting)

- Concerns relating to the client-practitioner therapeutic relationship

- State licensure issues

- Need for more rigorous research to help support the use of telehealth

- Personality 
Why Telehealth in Early Intervention?

- Telehealth is recognized for OT, PT, and Speech as an appropriate and effective model to provide early intervention services

- Increases clinical outcomes compared to traditional methods of care Increases participation of child and family

- Care can take place in the natural environment of the child, and during normal routines of the family (i.e. feeding during regular mealtime)

- Utilizes the approach of coaching, which helps to empower families with the care of their child

Are there any clients that you currently have or may have had in the past that you think would have benefited from telehealth?

\section{What is the Coaching Model?}

- Setting goals with the family and helping to outline a plan to achieve these outcomes

- Client-centered approach of educating caregivers and treating child collaboratively

- Promotes parent-child interactions

- Improves caregiver efficacy, responsiveness to the child, and

- Promotes participation of the child

- Increases clinical outcomes compared to traditional methods of care Graham, Rodger, \& Ziviani, 2013; Kessler \& Graham, 2015; Litte, Wallisch, Pope \&
Dunn, 2018; Kairy et al, 2009 .

\section{Case Examples}

Phil, who is ten months old, lives at home with his mother and his father is employed through the military. He is receiving therapy services for developmental delays. Father wants to be a part of Phil's treatments, but cannot due to traveling and changing schedules from his career. Susie is a two year old with sensory processing disorder. She is under joint custody of her mother and father, who live in differenent towns. Both parents want to be present for every therapy session to stay up to date on treatments ant know how to implement any changes at home.

How can telehealth promote participation of both parents? How can telehealth help with the communication between parents?

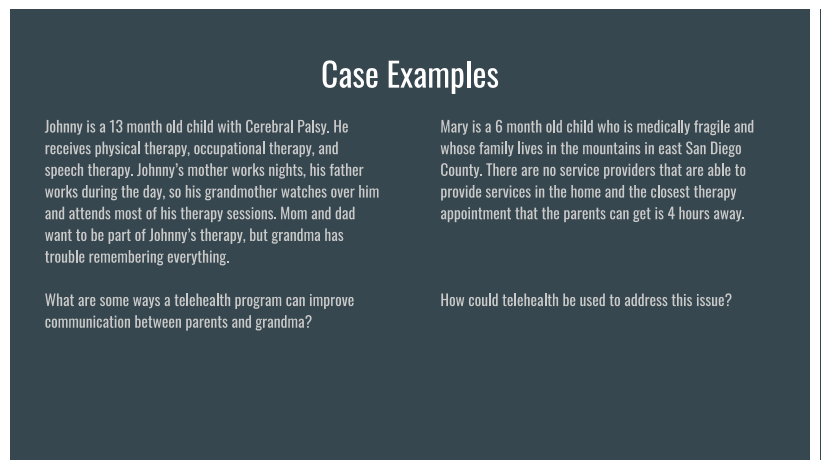

"Especially [for] the more rural families where l've had

trouble saying no to in the past. I've gone out of my

way for those kiddos, when they [Regional Center]

can't find a therapist to go out and see them... I know

for me, I've had to turn down families, that maybe

telehealth would have allowed me to work ... So, if I'm

able to provide my expertise and my training to them

and this is the best option to do it versus having

nothing, then I'm open to definitely exploring

telehealth, especially in those instances"

-Occupational Therapist.

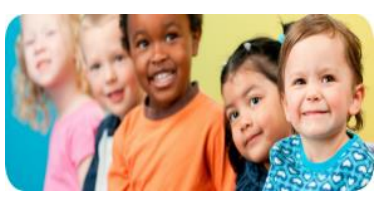

\section{What Does the Literature Say?}

Perceptions vs Experiences
- The key to the implementation of a successful telehealth program is provider's acceptance (Serwe, 2018)

- "Perceptions can serve as facilitators or barriers to the uptake of new technology..." (Mammen et al., 2018)

- It is important to understand service provider's experiences with telehealth (Serwe, 2018)

- Providers tend to participate via telehealth based on client need (Serwe, 2018) 
Most Reported Benefits- Therapist's Perspectives of Telehealth

Providers Who Have Used Telehealth:

Improve accessibility of services/care $(88 \%)$

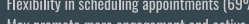

May promote more engagement and active participation by

the client/caregiver (63\%)

Reduce travel time $(63 \%$

Prevention of delays to see a specialist ( $38 \%$ )

A cost-effeetive tool for providing services $(38 \%)$

Helps with transitions within the home environment

8. Mitigate cancellations $(19 \%$
Providers Who Have Not Used Telehealth:

Improve accessibility of services/care $(87 \%$ eduling appointments $(77 \%)$ Reduced travel time $70 \%$ Prevention of delays to see a specialist $(60 \%)$ the by the client//caregiver $33 \%$ \%

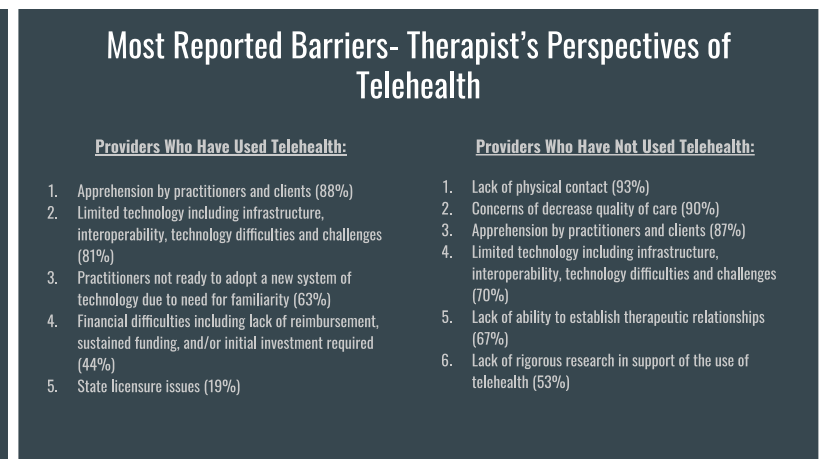

Most Reported Benefits- Caregiver's Perspectives of Telehealth

Caregivers Who Have Used Telehealth:

Improved flexibility in appointment scheduling (100\%)

Decreased travel time to appointments $150 \%$

Improved access to healtheare $(50 \%)$

Easier to receive services in home and during normal

Method of collaboration with the therapist $(50 \%$

6. "I love everything about itt" (50\%)
Garegivers Who Have Not Used Telehealth:

Decreased travel time to appointments $(77.8 \%)$ Improved flexibility in appointment schedulung $(66.7 \%$ Easier to receive services in home and during normal schedules $(66.7 \%)$

Improved access to healthcare $(33.3 \%$

Method of collaboration with therapist (22.2\%)

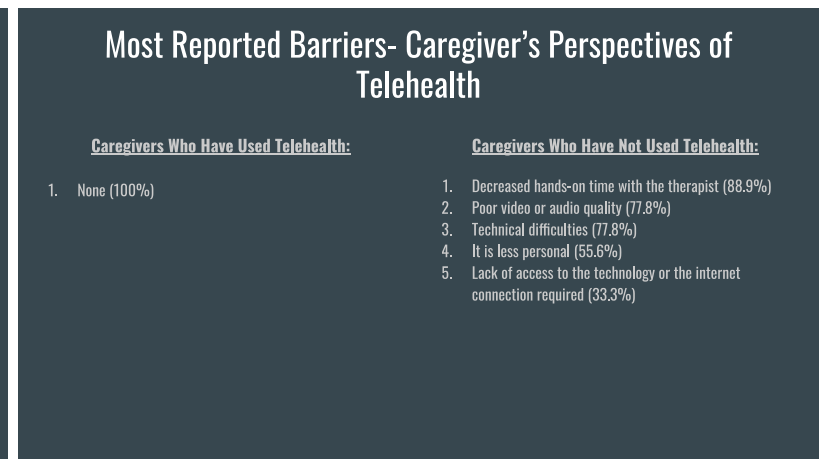

Provider's Perceptions of Telehealth

- "I think it is an easier thing for them to get out of I show up to their house and they can't really not answer the door. They could just be like oh my computer broke or I ran out of battery. So they have more control or power whether or not the kiddo will get

"Once therapists have a routine of how they do things and it's a system that works well. You are reluctant to change." - Occupational Therapis

- "lam apprehensive as I find it easier to have in person conversations sol can use language and hands on techniques to ensure full comprehension. However, also feel that maximizing services and availability of services to people is beneficial." -Physical Therapis
Provider's Experiences with Telehealth:

"We actually have a better cancellation rate for telehealth than we did for in the clinic our overal celenealth han we did for in the clininic... our overal ranges anything more than $20 \%$."-Occupational

- "There is this trend in pediatric therapy where parents just drop off their kid at the clinic and are not involved in session, telehealth allows the parents to be more involved with better carryover at the home."-Occupational Therapist

- "It's because it's an emerging area for professionals, so not everyone understands what online sessions entail. And not everyone understands that therapy doesnt whole session." - Occupational Iherapist

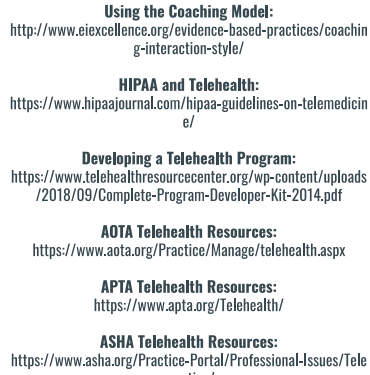

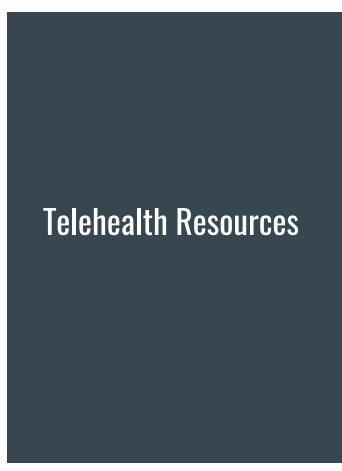
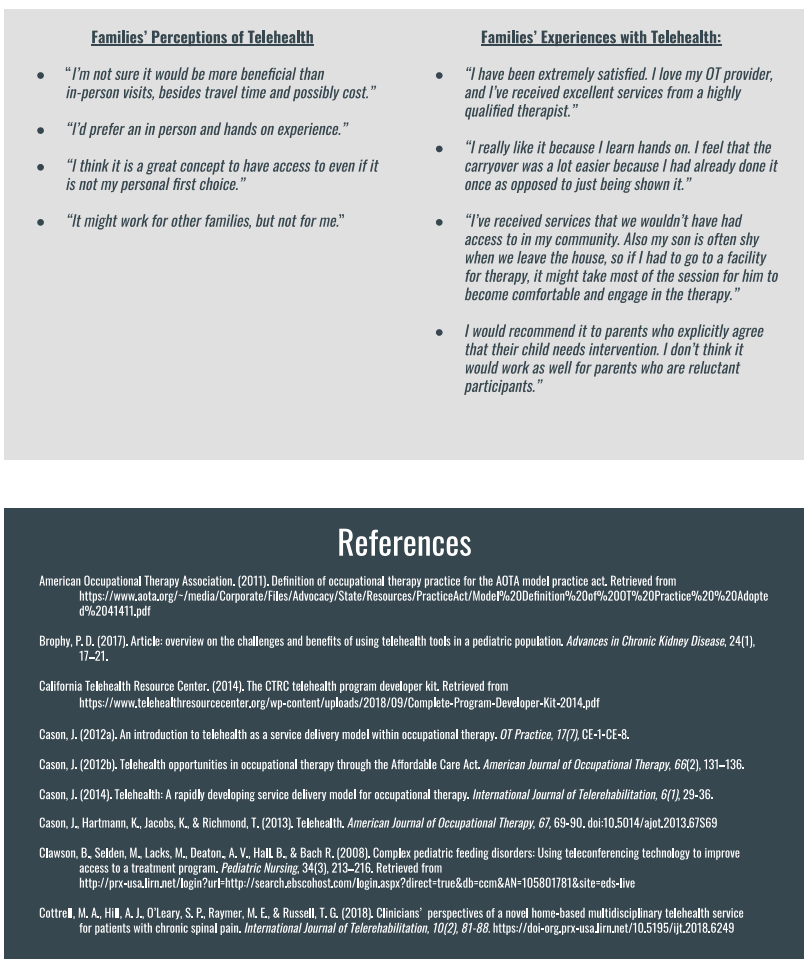


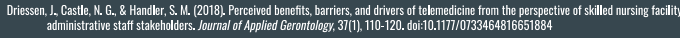

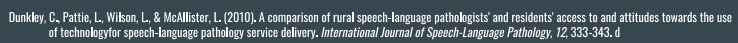

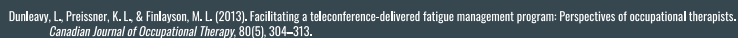

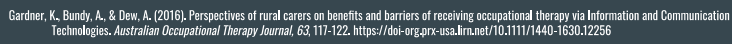

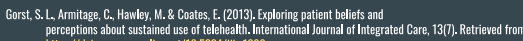

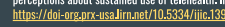

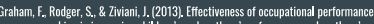

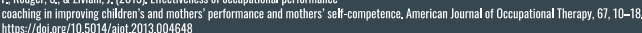

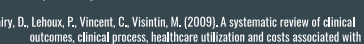

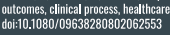

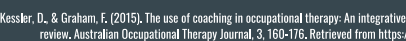

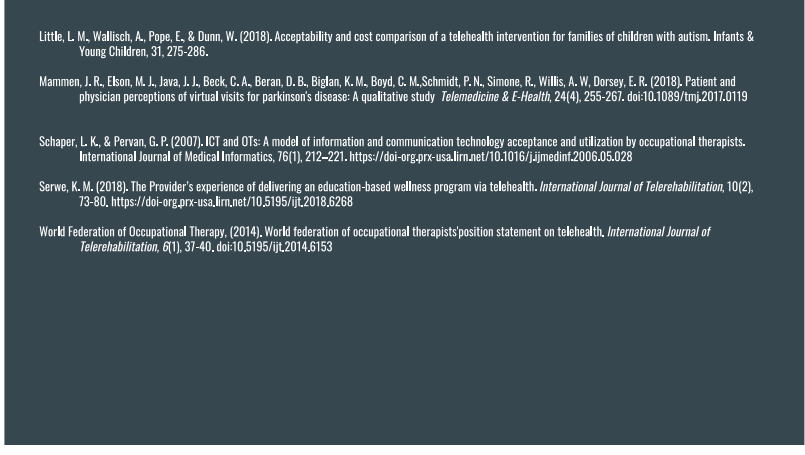

thank you

\section{Questions?}

